\title{
Day-to-day variability of ionosphere electron density during solar minimum derived from FORMOSAT-7/COSMIC-2 measurements
}

\author{
Panthalingal Krishanunni Rajesh ${ }^{1}$, Charles C. H. Lin ${ }^{1, *}$, Jia-Ting Lin ${ }^{1}$, Chi-Yen Lin ${ }^{2}$, Jia Yue \\ Tomoko Matsuo ${ }^{4}$, Shih-Ping Chen ${ }^{1}$, and Chia-Hung Chen ${ }^{1}$ \\ ${ }^{1}$ National Cheng Kung University, Tainan City, Taiwan \\ ${ }^{2}$ National Central University, Taoyuan City, Taiwan \\ ${ }^{3}$ NASA Goddard Space Flight Center, Maryland, U.S.A. \\ ${ }^{4}$ University of Colorado, Boulder, U.S.A.
}

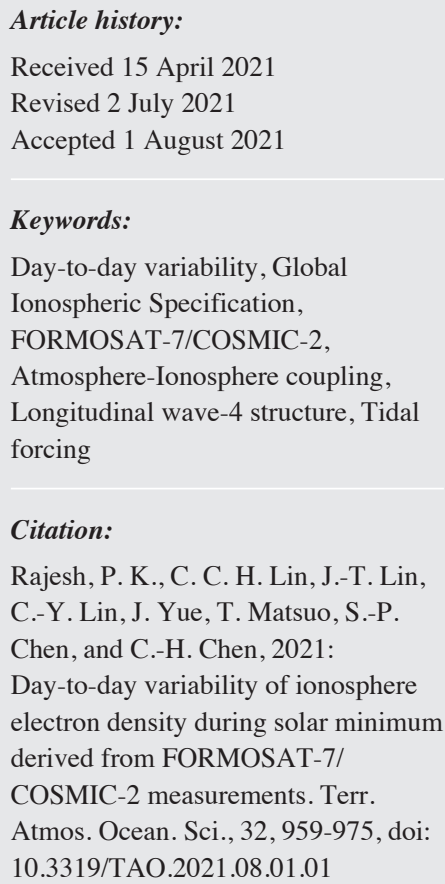

Received 15 April 2021

Revised 2 July 2021

Accepted 1 August 2021

Keywords:

Day-to-day variability, Global Ionospheric Specification, FORMOSAT-7/COSMIC-2, Atmosphere-Ionosphere coupling, Longitudinal wave-4 structure, Tidal forcing

Citation:

Rajesh, P. K., C. C. H. Lin, J.-T. Lin, C.-Y. Lin, J. Yue, T. Matsuo, S.-P. Chen, and C.-H. Chen, 2021: Day-to-day variability of ionosphere electron density during solar minimum derived from FORMOSAT-7/ COSMIC-2 measurements. Terr. Atmos. Ocean. Sci., 32, 959-975, doi: 10.3319/TAO.2021.08.01.01

\begin{abstract}
This study examines the day-to-day variability of low-latitude ionosphere using global ionospheric specification (GIS) electron density profiles derived from FORMOSAT-7/COSMIC-2 radio occultation measurements during a deep solar minimum period of August 2019 to July 2020. The measurements reveal significant daily variations over dayside low latitudes, yielding about $10-20 \%$ standard deviation in equinoxes, $20-30 \%$ in solstices, reaching $40-50 \%$ in winter. The nighttime deviations could be $30-60 \%$, being largest in solstices. Day-to-day variations are also observed in the longitudinal wave- 4 structures. The period mostly remained geomagnetically quiet except for some moderate disturbances on a few days. Tidal decomposition of the GIS electron density shows that in-situ forced migrating diurnal (DW1) terdiurnal (TW3) oscillations and the background zonal mean yield only 25\% of the daily variations despite accounting for almost $75-90 \%$ of the observed electron density. Thus, forcing from lower atmosphere dominates the contribution $(\sim 75 \%)$ to the observed daily variations. Only about one third of this lower atmospheric forcing comes from the migrating semidiurnal SW2 and the usually investigated nonmigrating diurnal eastward DE2, DE3, stationary planetary wave SPW3, SPW4, and semidiurnal eastward SE1, and SE2 components. The residual tides other than those mentioned above, including secondary waves through non-linear interactions and other planetary waves, thus significantly influence the day-to-day variations in electron density and modify the longitudinal wave structures.
\end{abstract}

\section{INTRODUCTION}

Day-to-day variability is one of the most intriguing as well as challenging aspects of current ionospheric research. It is intriguing because it provides detailed insights into how the thermosphere-ionosphere system attains a new equilibrium state when one or several of the driving forces or energy inputs deviate from an expected mean behavior. Many of the current theoretical models are capable of reproducing the state of the ionosphere relatively well for specific forcing input parameters and/or boundary conditions, but they fail to reproduce the observed day-to-day variability of the

\footnotetext{
* Corresponding author

E-mail:charles@mail.ncku.edu.tw
}

ionosphere. A better understanding of causes of the day-today variability is essential for improving the accuracy of physics-based models of the ionosphere. It is challenging mainly in two ways; (1) the lack of daily global observations, and (2) the complex nature of day-to-day variability resulting from various driving forces. While space-based observations have an important role in providing continuous measurements when ground-based observations are not available, the spatial and/or temporal coverages are often insufficient. On the other hand, continuous global measurements of the ionosphere are essential to comprehend varying influences of different types of the external forcing on the day-to-day variability. 
The external forcing includes variations in photoionization, coupling from lower atmosphere interactions and the forcing through high latitudes. The high latitude energy input, usually associated with magnetic disturbances, drives large-scale dynamic variations in electron density that could last several hours or even days (Fejer et al. 1979; Gonzales et al. 1979; Blanc and Richmond 1980; Prölss 1993; Tsurutani et al. 2004; Lin et al. 2005a, b; Huang 2019). The tidal coupling from lower atmosphere is more periodic, occurring as harmonics of a day, and is produced by the upward propagating tides and waves that are excited by the heating due to the absorption of solar radiation at various levels in the atmosphere (Forbes et al. 2008). The tides dissipate in the mesosphere-lower thermosphere (MLT) region around $80-150 \mathrm{~km}$, where individual atmospheric species starts adopting a diffusive equilibrium state, depositing their energy and momentum, and modifying the background temperature and wind (Forbes et al. 2003, 2008). Winds in this region essentially drive the day-time E-region dynamo (e.g., Rishbeth 1997 and the references therein), generating electric fields and currents that determine the plasma distribution through equatorial plasma fountain, which produces the equatorial ionization anomaly (EIA) crests (Appleton 1946; Anderson 1973).

Observational evidence for the existence of solar diurnal and semi-diurnal tidal variations of electron density in the ionosphere F-region by the modulations of dynamo electric field by horizontal winds was reported by Martyn (1947) based on ionosonde observations dating back to 1937. Subsequent studies indicated that the temporal and spatial variations of lower and upper atmospheres are coupled through chemical and dynamical processes and the two regions cannot be treated as independent (Bauer 1958; Fejer 1964; Fraser and Thorpe 1976; Walker 1981; Taubenheim 1983; Kazimirovsky and Kokourov 1991; Forbes et al. 2000; Hagan and Forbes 2003). The modulation of the neutral wind by tides contribute to corresponding periodic variations of the EIA electron density (England et al. 2010). Most prominent features of such periodic variations are the longitudinal wave- 3 and wave- 4 modulations of the EIA crests in a fixed local-time frame, which are produced by the upward propagating non-migrating tides (Sagawa et al. 2005; England et al. 2006; Immel et al. 2006; Hagan et al. 2007; Lin et al. 2007; Fang et al. 2009). Following such observations, tidal decomposition of electron density and TEC were performed to deduce the contribution of various atmospheric modes to ionospheric variability, particularly over the EIA region (Pancheva and Mukhtarov 2010, 2012; Pedatella and Forbes 2010; Lin et al. 2012, 2019; Pedatella et al. 2012, 2016; Chang et al. 2013a, b; Chen et al. 2013; Fang et al. 2013, 2018; Wang et al. 2015; Lean et al. 2016; Zhou et al. 2016; Forbes et al. 2021).

However, such observations of global maps of the longitudinal EIA structures are usually constructed by combin- ing several (20 - 45) days of observations (e.g., Immel et al. 2006; Lin et al. 2007), at the expense of any information about the day-to-day variations. To determine the dominant tidal components that contribute to the observed longitudinal EIA patterns, global observations that cover all longitudes and local times are required. In most of the studies so far, this is accomplished by applying a 20-45 day moving window on sparsely sampled observations (e.g., Lin et al. 2012; Pancheva and Mukhtarov 2012; Chang et al. 2013a, b). This hinders any examination of the daily changes of the amplitudes of different tidal components, and in understanding their possible interactions that could give rise to complex ionospheric density modifications and drive variability of the longitudinal structures.

This limitation of having daily global ionospheric observations could now be overcome with the recent development of Global Ionospheric Specification (GIS) that reconstructs the three-dimensional (3D) electron density from assimilative analysis of slant Total Electron Content (TEC) measurements by space-based radio occultation (RO) and ground-based Global Navigation Satellite System (GNSS) receivers (for details, see Lin et al. 2017). The potential of the daily GIS density maps for examining the tidal modes that influence the ionospheric variations have been demonstrated by Lin et al. (2019) by using FORMOSAT-3/COSMIC (F3/C) RO data during a stratospheric sudden warming (SSW) event in 2009. With the launch of FORMOSAT-7/ COSMIC-2 (F7/C2) mission, 3D global ionosphere specification (GIS) electron density maps are now generated at Taiwan Analysis Center for COSMIC every hour on each day, with $2.5^{\circ} \times 5^{\circ}$ horizontal resolution, and $20 \mathrm{~km}$ vertical resolution covering the regions above $150 \mathrm{~km}$ to the $\mathrm{F} 7 / \mathrm{C} 2$ orbit altitude.

Note that the F7/C2, which receives both GPS and GLONASS signals, yields about two times more occultations than its predecessor F3/C mission, and densely samples the equatorial and low-latitude regions owing to the low inclination angle. The GIS electron density maps produced with the F7/C2 data thus provides a new opportunity to examine the day-to-day variations in the low-latitude ionosphere, to the extent it was not possible earlier. Note that the GIS density have been thoroughly validated by using manually scaled ionosonde measurements by Lin et al. (2020a). In a recent study, Lin et al. (2020b) applied the GIS measurements to examine the local time and vertical characteristics of quasi-6-day oscillations in ionosphere following the Antarctic SSW of 2019. Rajesh et al. (2021) showed extreme ionosphere responses to the minor magnetic storm of 5 August 2019, by comparing the vertical electron density distributions from GIS on the storm day and the pre-storm day. This study further makes use of the daily GIS data during a one-year period of August 2019 to July 2020, and for the first time, examines the day-to-day variability of the longitudinal structures of EIA. The low-latitude ionospheric 
variations are addressed here not just to emphasize on the F7/C2 contribution, also because the ionosphere responses to the lower atmospheric forcing are more pronounced there. Tidal analyses of the GIS electron density have been carried out, and the dominant tidal modes that contribute to the observed variability are discussed.

\section{DAY-TO-DAY GIS MAPS OF EIA STRUCTURES BY F7/C2}

Hourly GIS density maps are routinely generated by using the F7/C2 observations since 1 August 2019 with a delay of approximately 2-days and are made available at the National Cheng Kung University web platform (http://formosat7.earth.ncku.edu.tw) for the F7/C2 data products (see Data Availability Statement for details of accessing the GIS data). Figure 1 displays the global maps of electron density at 200,300, and $400 \mathrm{~km}$ altitudes at fixed local time (LT) 1400 on four consecutive days from 19 to 22 September 2019. The overall density patterns appear to be nearly identical on all the four days, with well-developed EIA crests typical of equinox conditions, being prominent at $300 \mathrm{~km}$. The altitude variation of electron density is also mostly similar for all the days plotted. However, what makes the figure remarkable is the distinct longitudinal wave-4 peak structure seen on all the four days, approximately centered over $90^{\circ} \mathrm{W}$ (East Pacific Ocean), $30^{\circ} \mathrm{W}$ (Atlantic Ocean), $90^{\circ} \mathrm{E}$ (Indian Ocean), and $150^{\circ} \mathrm{E}$ (West Pacific Ocean) longitudes respectively, which appear pronounced at $300 \mathrm{~km}$ altitude.

Upon closer inspection, day-to-day differences could be noticed in the enhanced EIA regions in the figure. Though the locations of the peaks apparently remain fixed, the corresponding relative amplitudes are not, either getting enhanced or becoming weaker from day to day. Over the East Pacific, the crests become much weaker on 20 September, but are enhanced on the next two days with notable NorthSouth asymmetry in crest density. A similar daily pattern could be seen in the case of the peak over Atlantic Ocean, where the crests gradually enhance from 19 to 21 September and weaken on the next day. Note that the southern crest here is stronger than the northern crest on all the four days. Over the Indian Ocean, the southern EIA peak remains mostly identical except on 21 September when it is weaker. On the other hand, the northern crest is much weaker on all the days except on 22 September when it is stronger over the entire $0-20^{\circ} \mathrm{E}$ longitudes. The EIA crests over the West Pacific region enhance or weaken on alternative days, with the North-South crest density also following a similar pattern.

Additionally, in Fig. 1, the wave-4 pattern is barely discernible at $200 \mathrm{~km}$ where the EIA enhancement is still noticeable. However, weaker but distinct wave-4 modulations exist at $400 \mathrm{~km}$ altitude at $1400 \mathrm{LT}$. At lower altitudes, loss processes may alleviate any impact of the longitudinal modulation of the EIA crests. Though not included in the figure, it is worth adding that the wave- 4 structure quickly disappeared above $450 \mathrm{~km}$ altitude. Despite this, day-to-day variations in the electron density distribution is evident over all the altitudes displayed. Note that Fig. 1 displays first such global fixed local times maps, revealing the day-to-day and vertical characteristics of EIA, and that of the wave-4 modulation from daily electron density measurements without any multi-day averaging involved.

Figure 2 further demonstrates this advantage of using GIS data for the investigation of the day-to-day variability, wherein the latitude and local-time maps of daily electron density at $300 \mathrm{~km}$ altitude during the 1-year period of F7/ C2 observations spanning over 2019 - 2020 are plotted. The rows are centered over the longitude sectors of the wave4 peak structure depicted in Fig. 1. The latitude distribution displays distinct EIA crests in both the hemispheres, peaking at around $15^{\circ}$ magnetic latitude. A seasonal pattern yielding stronger electron density during equinox and reduced values in solstice is also evident. Pronounced annual asymmetry or December anomaly (e.g., Rishbeth and Müller-Wodarg 2006) with more density in December solstice than in June solstice could be noticed in the Southern Hemisphere ( $\mathrm{SH})$, though is less apparent in the Northern Hemisphere (NH). The latitude distribution further shows noticeable North-South asymmetry, with the December Solstice density in the SH being larger compared to that in the $\mathrm{NH}$. The hemispheric asymmetry is less noticeable in June solstice. The figure also illustrates the seasonal or winter anomaly (e.g., Torr and Torr 1973; Torr et al. 1980) in the local time distribution (shown for $\mathrm{NH}$ ), with peak density occurring at earlier local times in the winter months $(\sim 1200$ LT) compared to summer ( 1500 LT).

In addition to the general patterns described above, Fig. 2 also demonstrates strong daily variations in the electron density. The standard deviation with respect to 10-day average quantifies the daily variations, showing larger variability over the EIA crest latitudes and falls off at higher latitudes. The daily variations show a similar seasonal trend as in the density values, peaking during equinoxes and less deviation in solstices. The day-to-day variability is more noticeable in the local-time map over $15^{\circ} \mathrm{N}$ magnetic latitude, with the variability more noticeable during daytime. The standard deviation peaks between 1200 and 1600 LT and yields lowest values during midnight-dawn period. The day-to-day variability reported here include the effects of local-time variations in sunrise/sunset times and seasonal transitions. Note that there are also longitudinal differences in the seasonal behavior, EIA crest separation, crestto-trough density, etc. Nevertheless, the overall pattern is mostly identical, and the longitudinal variation will be addressed in a separate study.

The latitude, local-time and seasonal variability in Fig. 2 generally agree with that reported in the earlier studies (Rishbeth and Mendillo 2001). In terms of percentage 


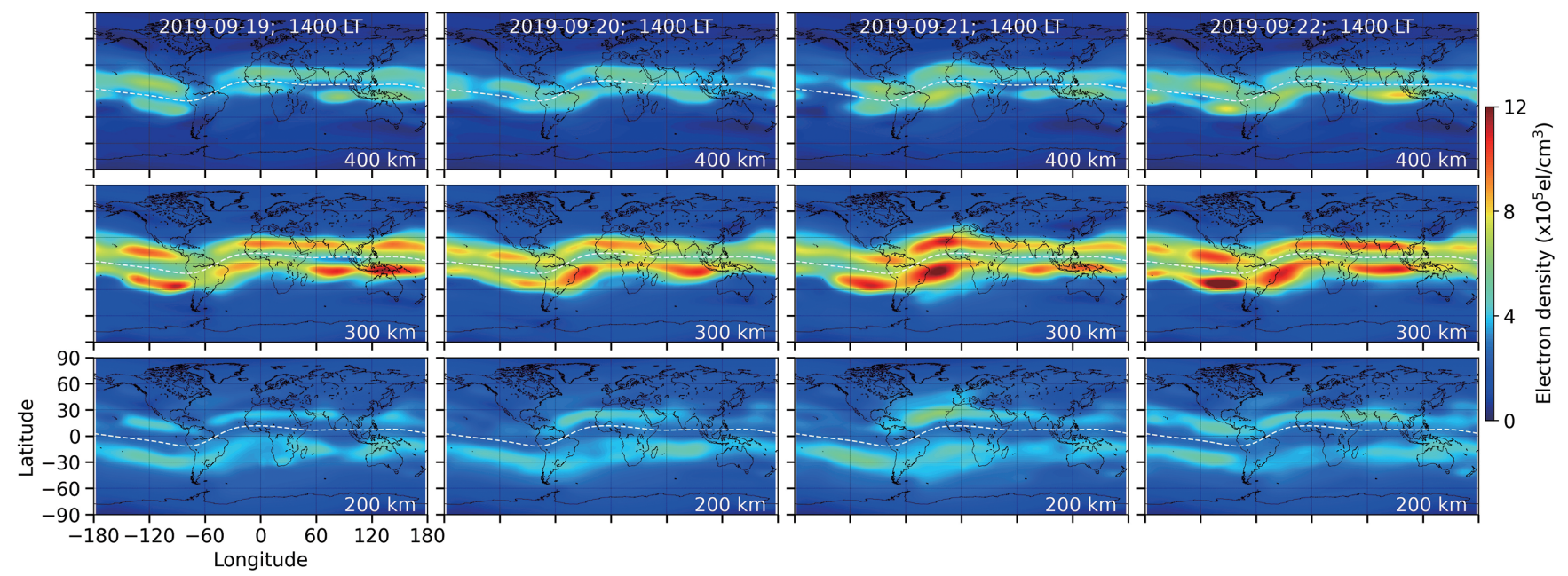

Fig. 1. GIS density maps at 1400 LT, (left to right) on four consecutive days during 19 - 22 September 2019, at (top to bottom) 400, 300, and 200 $\mathrm{km}$ altitudes. The white dotted line on each plot denotes the magnetic equator.
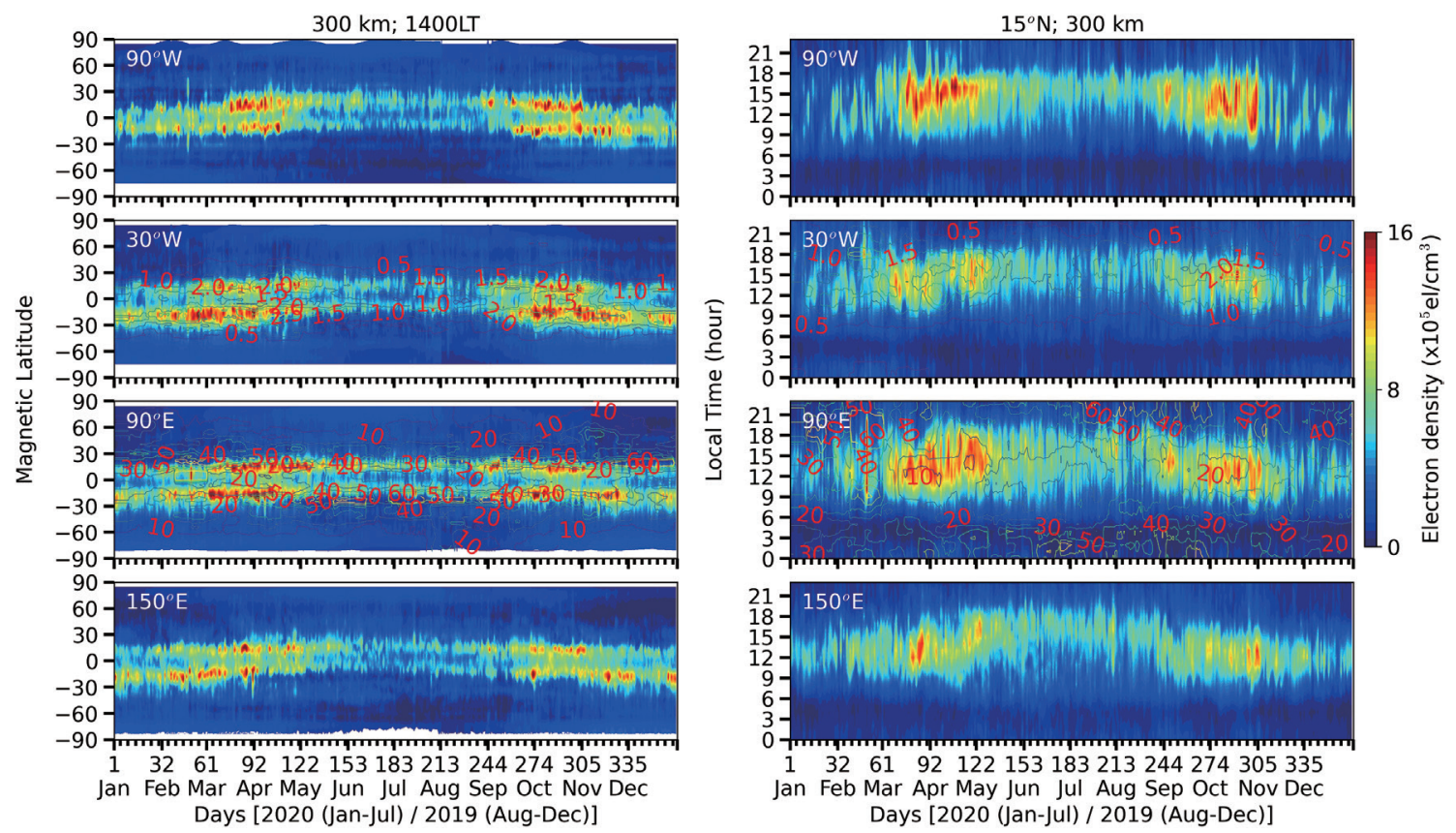

Fig. 2. Daily GIS density at $300 \mathrm{~km}$ during 2019 - 2020 (left) as a function of magnetic latitude at $1400 \mathrm{LT}$ and (right) as a function of local time at $15^{\circ} \mathrm{N}$ magnetic latitude (top to bottom) over the wave- 4 peak longitudes of $90^{\circ} \mathrm{W}, 30^{\circ} \mathrm{W}, 90^{\circ} \mathrm{E}$, and $150^{\circ} \mathrm{E}$. The contour lines in the second and third panels are respectively the absolute and percentage standard deviations from a 10-day running average. Note that the days from 1 January to 31 July (DOY 1 - 212) are the observations in 2020, and the remaining days are from 2019 . The $\mathrm{x}$-axis major ticks indicate the 1 st of every month with the corresponding DOY noted below, and the minor ticks corresponds to the days 5, 10, 15, 20, 25, and 30 of each month as applicable. 
values, during daytime, the standard deviation is lowest in the equinoxes $(10-20 \%)$ over low latitudes, increases in solstices (20 - 30\%), giving maximum deviation in winter (40 - 50\%). Larger percentage deviations $(30-40 \%)$ are seen to the poleward of EIA crests, becoming more than $60 \%$ in winter, but is much smaller $(\sim 10 \%)$ beyond $60^{\circ}$ magnetic latitude. At night, the percentage deviation over low latitudes is larger (30-60\%), with more variability during pre-midnight period in winter and during post-midnight hours in summer. A 10-day running average is used here as reference to examine the deviations to minimize the effect of seasonal variations.

For a more quantitative description of the daily variations, the electron density at $1400 \mathrm{LT}$ over EIA crest $\left(15^{\circ} \mathrm{N}\right.$ magnetic latitude), when the deviations maximize, are examined in Fig. 3. The figure reveals significant day-to-day variations superimposed over a seasonal pattern that gives about $100-150 \%$ more density in equinox than in solstice months. To provide a better perception of the daily variations instead of showing the mean value and standard deviation, the daily deviations with respect to the average are plotted here. The day-to-day differences on an average account for about $15-30 \%$ variation in the electron density with respect to a 10-day running mean, at times yielding above $50 \%$ variation, and is more significant in the winter solstice months, especially over $90^{\circ} \mathrm{W}$ longitude. Note that, in Fig. 3, the background electron density in winter already starts decreasing by $1400 \mathrm{LT}$ (winter anomaly), thus yielding larger percentage deviation compared to other seasons. The deviation of the absolute electron density, on the other hand, is more pronounced in the equinox months.
The F10.7 solar flux variation may cater for only part (within $\pm 3 \%$ ) of this day-to-day variability, indicating possible contributions from other dynamic processes. Further, the daily maximum $\mathrm{Kp}$ values were below 6 , with only 12 days with $\mathrm{Kp}>4$ and in which on 5 occasions it exceeded 5. The $\mathrm{Kp}$ remained below 3 for more than 300 days during this period. As the neutral wind in this region plays dominant role in controlling the dynamic variability, tidal decomposition of the GIS density is further carried out to understand how the ubiquitous day-to-day differences in the ionosphere could be influenced by the variabilities that occur far below.

\section{DAY-TO-DAY VARIATIONS OF TIDAL MODULATIONS IN F-REGION}

The hourly GIS data provide a unique opportunity to examine the variabilities in the tidal amplitudes that influence the day-to-day ionospheric dynamics, and to understand how tidal changes drive the observed density differences. In addition, the daily relative amplitudes of various tidal modes will also influence the day-to-day variations of the longitudinal wave pattern. While the wave- 4 structure exhibits itself as a modulation of the EIA, the associated daily differences in its amplitude points to the complex nature of the processes influencing the atmosphere-ionosphere coupling and the resulting electrodynamics. For example, the wave- 4 and wave- 3 longitudinal variations have primarily been associated with non-migrating diurnal tides (DE2 and DE3) in the MLT region, with additional components contributing to the variability depending on year and time of the year (Forbes et al. 2008; Chang et al. 2013b). The tidal
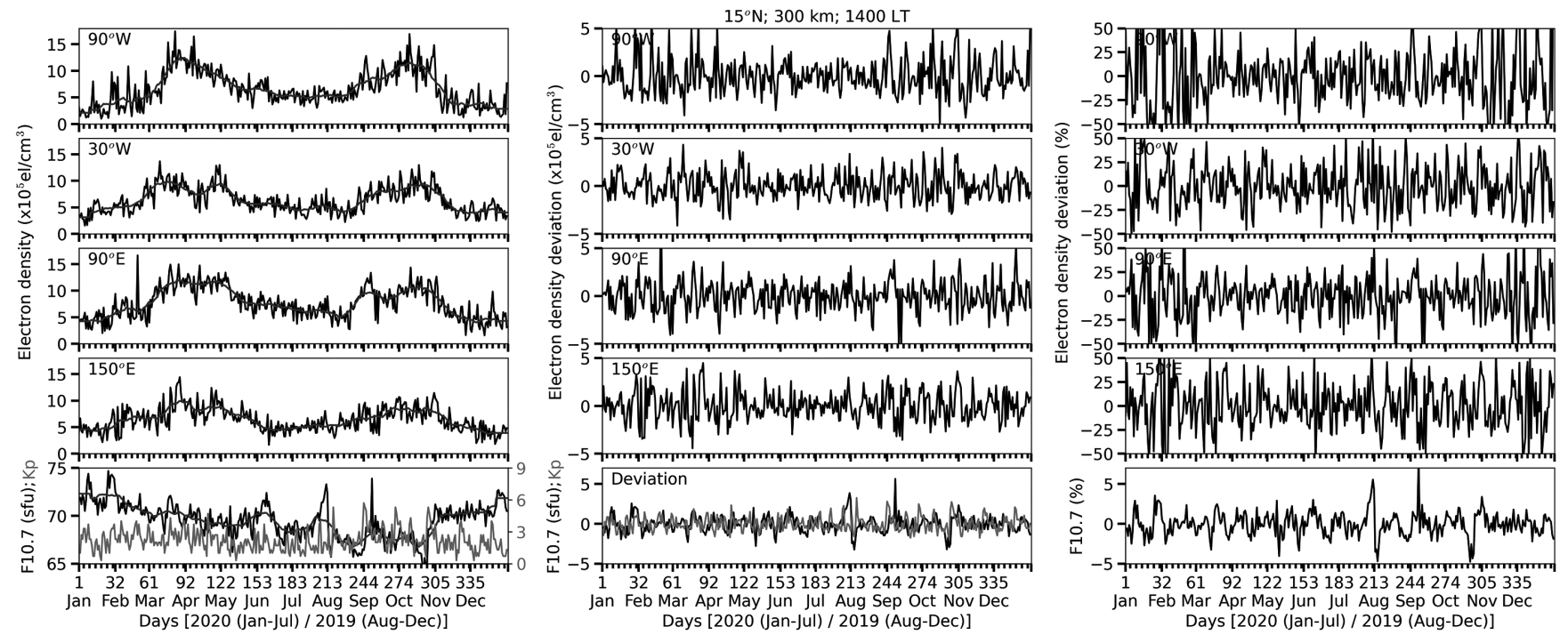

Fig. 3. Day-to-day variability at the Northern EIA crest. (Left) Daily GIS electron density at $1400 \mathrm{LT}$ over $15^{\circ} \mathrm{N}$ magnetic latitude and $300 \mathrm{~km}$ altitude, (top to bottom) centered over the wave- 4 peak locations of $90^{\circ} \mathrm{W}, 30^{\circ} \mathrm{W}, 90^{\circ} \mathrm{E}$, and $150^{\circ} \mathrm{E}$ longitudes, with the daily F10.7 indices and the daily maximum Kp values (in grey color with axis labels to the right) in the lower panel. The blue line represents a 10-day running average, depicting mainly the seasonal pattern. (Middle) Same as left panels but shows day-to-day variations with respect to the 10-day running average, and (right) the corresponding percentage deviations. 
analysis of the GIS results carried out in this study follows the approach outlined by Lin et al. (2019).

The hourly GIS electron density within $\pm 40^{\circ}$ magnetic latitudes, at every 1-hour UT interval during 1 August 2019 to 31 July 2020, are used to extract periodic oscillations in ionosphere electron density at different altitudes between 100 and $700 \mathrm{~km}$, and in the corresponding TEC values. The analysis involves fitting harmonic functions as expressed below (for e.g., Zhang et al. 2006; Forbes et al. 2008), to the GIS electron density and TEC (denoted by $X$ ),

$$
X\left(t_{U T}, \lambda\right)=\bar{X}+\sum_{n=0}^{3} \sum_{s=-4}^{4} A_{n, s} \cos \left[n \Omega t_{U T}-(s) \lambda+\theta_{n, s}\right]
$$

where $n(=0$ to 3$)$ is the subharmonics of a solar day, $s(=-4$ to 4 ) is the zonal wavenumber, $t_{U T}$ is the universal time, $\Omega$ is the rotation rate of the Earth $(2 \pi /$ day $), \lambda$ is the longitude, $\bar{X}$ is the zonal and diurnal mean value corresponding to $X$. Least squares solutions are used to obtain the amplitudes $\left(A_{n, s}\right)$ and phases $\left(\theta_{n, s}\right)$ of migrating $(n+s=0)$ and nonmigrating $(n+s \neq 0)$ tidal components and stationary planetary waves as a function of latitude. Here, wave patterns propagating eastward (westward) corresponds to $s>0(s<0)$, and $n=1,2,3$ respectively represents diurnal, semidiurnal, and terdiurnal signatures of the electron density oscillations.

In the following descriptions and discussion, the generally accepted tidal nomenclature is adopted, where the first two letters of a given oscillation represent the period (D for diurnal, $\mathrm{S}$ for semidiurnal, and $\mathrm{T}$ for terdiurnal oscillations) and direction of propagation ( $\mathrm{E}$ for eastward and $\mathrm{W}$ for westward), with the following integer denoting the corresponding zonal wave number. The corresponding standing oscillations are denoted by $\mathrm{D} 0, \mathrm{~S} 0$, and $\mathrm{T} 0$, respectively and stationary planetary waves are represented using the letters SPW with the following integer denoting the corresponding wave number. Though the same tidal nomenclature is used here for the retrieved wave-like variations in the electron density, they are themselves not treated as tides. Hereafter, whenever a retrieved periodic component is represented by a tidal mode, it only suggests a corresponding oscillation in the electron density with a similar wavenumber and propagation as that of the tidal component and do not denote the tide itself. The same naming convention is followed here because it would be easier to relate the identified oscillations as the ionospheric response to the influence of the corresponding atmospheric tide. The possibilities where such oscillations may not be of atmospheric origin are discussed separately. Further, throughout the manuscript, the term "magnitude" is used to refer to the instantaneous amplitude of a retrieved tidal oscillation at a given local time.

\subsection{Migrating Tides}

Migrating tides are atmospheric oscillations with Sun- synchronous phase velocities, generated in the troposphere and stratosphere through the absorption of solar radiation by water vapor and ozone, and propagate vertically into thermosphere (Lindzen 1979; Forbes 1995). To examine the contribution of migrating tides in the observed day-today electron density variations during 2019 - 2020, the daily values of the westward propagating diurnal (DW1), semidiurnal (SW2), and terdiurnal (TW3) migrating tidal oscillations extracted from the GIS electron density are plotted in Fig. 4. The figure shows the daily variations of their magnitudes at the same location and time as in Fig. 3, as well as the latitude distribution of their relative amplitudes.

The most common feature in Fig. 4a is the semi-annual variation of the DW1, SW2, and TW3 components, though rather weak in the case of TW3. On an average, DW1 contributes to about $40-50 \%$ to the daily total electron density at $1400 \mathrm{LT}$ (Fig. 3), with associated day-to-day variations of about $10-15 \%$ in magnitude. The variation does reveal embedded multi-day oscillations, which appear pronounced and more periodic during September to November 2019. The SW2 magnitudes are only less than half of the DW1 values, however the periodic oscillations are more prominent except during the months of May to August. The TW3, though weakest among the migrating components, seems to contribute to rather incoherent electron density fluctuations. The pronounced oscillations seen in DW1 and SW2 during September to November 2019 appears to be suppressed in TW3. However, in other months TW3 does follow similar multi-day oscillations as in SW2.

Figure $4 \mathrm{~b}$ gives the latitudinal distribution of normalized daily zonal maximum amplitudes of the migrating oscillations in the electron density. The normalized amplitudes eliminate any effects of seasonal variation of the background ionosphere (Chang et al. 2013a). The annual pattern in Fig. 4b is in general similar to that shown by using F3/C electron density measurements and TEC (Pancheva and Mukhtarov 2012; Chang et al. 2013a). However, in the earlier reports, the latitudinal variation of DW1 amplitudes showed a single peak near magnetic equator, and the two peaks could not be well distinguished in SW2 throughout the year. Further, such studies provide much smoother daily variations. The GIS results resolve distinct North and South peaks in the DW1 response in electron density and show well separated and distinguishable peaks in the SW2 amplitudes, while also depicting their day-to-day variations.

Chang et al. (2013a) noted that the seasonal shift of peak latitude is lacking in the relative amplitudes of SW2 and TW3 when compared to DW1. In the GIS results, however, all the three tidal components exhibit a shift of the EIA peak latitudes with season. Further, the intra-annual variation of relative DW1 amplitude exhibits notable North-South asymmetry, peaking in NH occurring between DOY 70 and 130 and between DOY 240 and 300, mostly around equinoxes. The hemispheric asymmetry in DW1 response is strongest 

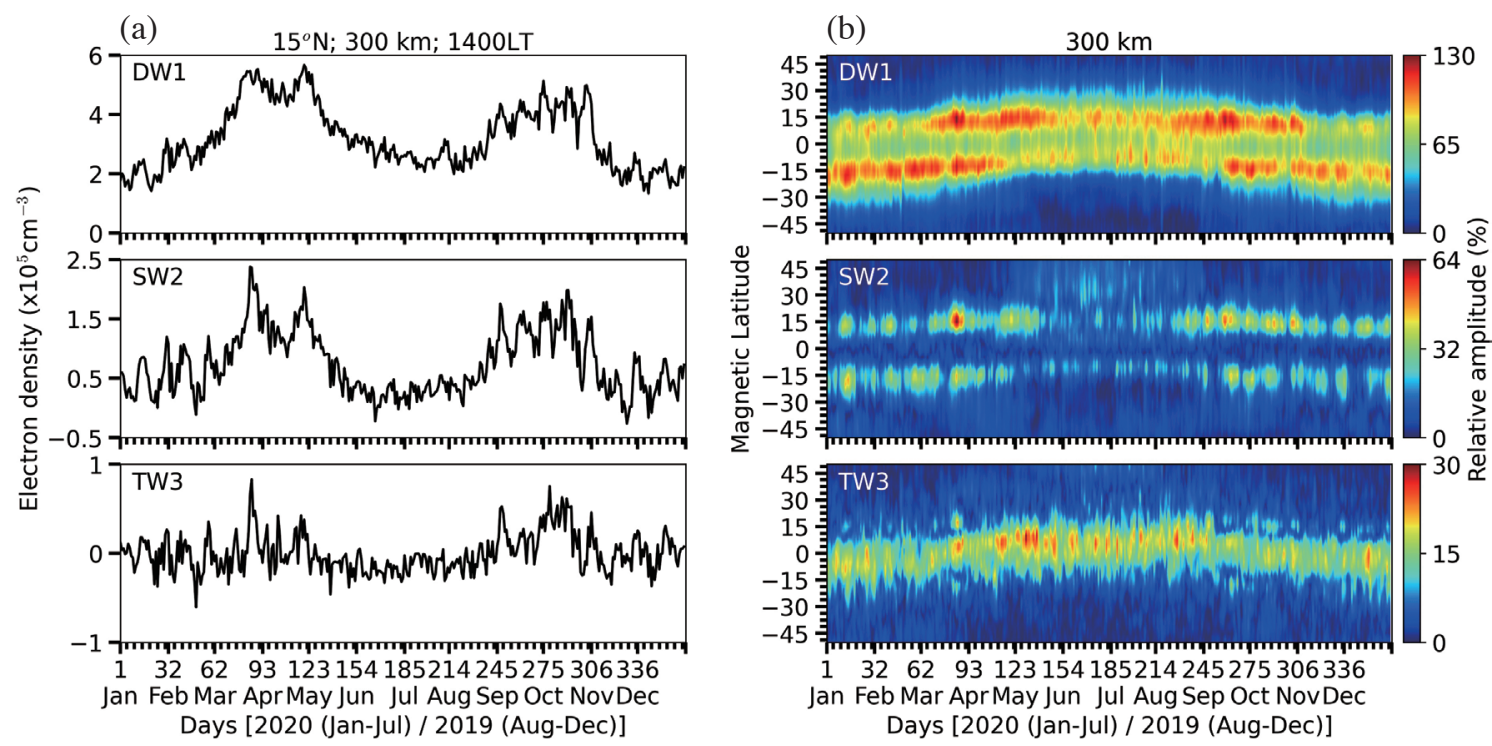

Fig. 4. The day-to-day variation of reconstructed electron density from the amplitudes and phases of migrating GIS oscillations during 2019 - 2020. (a) The daily magnitudes at $1400 \mathrm{LT}$ over $15^{\circ} \mathrm{N}$ magnetic latitude and $300 \mathrm{~km}$ altitude and (b) the daily zonal maximum relative amplitudes at 300 $\mathrm{km}$ as a function of magnetic latitude of (top to bottom) DW1, SW2, and TW3 oscillations. The relative amplitude is obtained by normalizing the absolute amplitude with the maximum value of the corresponding zonal and diurnal mean component on each day.

in the months of November to March. On the other hand, in $\mathrm{SH}$, stronger amplitudes appear for an elongated duration starting from DOY 240 of 2019 and persisting through DOY 100 of 2020. The SW2 amplitudes seem to weaken in June solstice months, with the duration of weaker amplitudes starting earlier (from May) and prolonging longer (through September) in the SH. Both DW1 and SW2 are strongest in the equinox months and SW2 remains consistently stronger in NH during September to November in 2019. The TW3 relative amplitudes peak over the equator and exhibit mostly an annual variation appearing pronounced from May through September (DOY 100 - 250). There seems to be a slight weakening of TW3 in the equinoxes compared to December solstice months. A much weaker secondary peak of TW3 could be noted over the EIA latitudes, except during June solstice months. Note that there are notable interannual variations in the seasonal pattern of tidal amplitudes (Forbes et al. 2008; Chang et al. 2013a), and the results in Fig. $4 \mathrm{~b}$ are hence subject to yearly variations.

\subsection{Non-Migrating Tides}

These are the atmospheric modulations that do not migrate with Sun from the perspective of an observer on Earth and derive their energy mainly from the latent heat release associated with deep tropical convection (Hagan et al. 1997; Hagan and Forbes 2002, 2003). Among these, DE2 and DE3 (diurnal eastward propagating wavenumber-2 and wavenumber-3) tides are known to primarily contribute to the wave-4 longitudinal variability in the local-time electron density structure.
Figure 5a displays the day-to-day variations of DE2 and DE3 during $2019-2020$ at $1400 \mathrm{LT}$ over $15^{\circ} \mathrm{N}$ magnetic latitude, and $300 \mathrm{~km}$ altitude, corresponding to the electron density values in Fig. 3. Unlike the migrating tides, the non-migrating tidal magnitudes are not zonally uniform at given local time, and hence the zonal maximum values are plotted here. Both the components show more high frequency fluctuations in their daily amplitudes compared to the migrating oscillations. Embedded multi-day oscillations could be seen in DE3, which become pronounced and more periodic during September to November 2019, as seen in the migrating components. Though the amplitudes of DE2 and DE3 more-or-less vary in the same range, the former appears to remain stronger on more days than the latter during the period considered here. The relatively smaller amplitudes of DE2 and DE3 suggest that these modulations only have a minor contribution to the observed day-to-day variability in Fig. 3.

The latitude distribution of the normalized zonal maximum amplitude of DE2 and DE3 at $300 \mathrm{~km}$ altitude during 2019 - 2020 are examined in Fig. 5b. Both DE2 and DE3 amplitudes are mostly comparable and are more prominent in the SH. The DE2 amplitudes are larger during March to August in $\mathrm{SH}$, and similar elevated amplitudes in $\mathrm{NH}$ occur during the June solstice (May to July) months. The DE3 amplitudes in SH is enhanced from July through October, during which stronger amplitudes also occur in the NH. The DE3 amplitudes are much diminished in November to December, especially in the NH. However, there is a period of secondary enhancement in the SH during January to May with a sporadic enhancement of $\mathrm{NH}$ response during March equinox. 

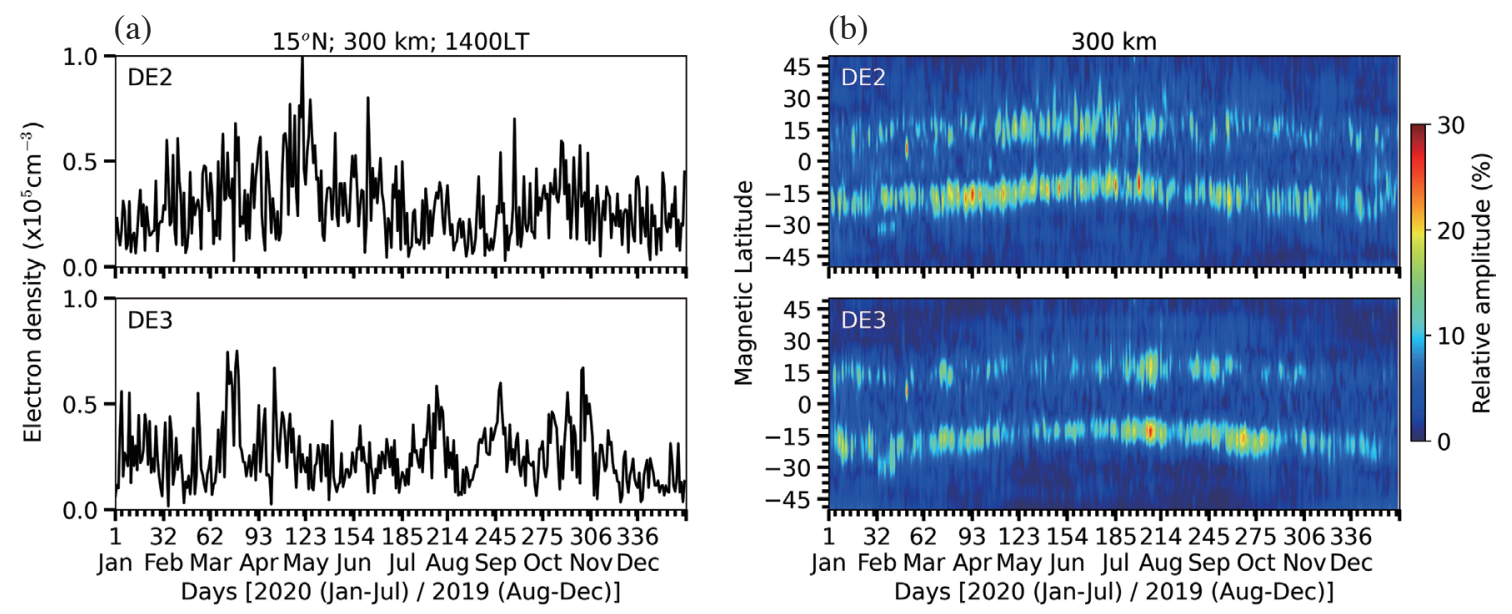

Fig. 5. The day-to-day variation of reconstructed electron density from the amplitudes and phases of non-migrating (top) DE2 and (bottom) DE3 GIS oscillations during 2019 - 2020. (a) The daily zonal maximum magnitudes at $1400 \mathrm{LT}$ over $15^{\circ} \mathrm{N}$ magnetic latitude and $300 \mathrm{~km}$ altitude and (b) the daily zonal maximum relative amplitudes at $300 \mathrm{~km}$ as a function of magnetic latitude. The relative amplitude is obtained by normalizing the absolute amplitude with the maximum value of the corresponding zonal and diurnal mean component on each day.

Despite significant inter-annual variations, Forbes et al. (2008) had portrayed a general picture of relatively stronger DE2 tides in December solstice months with peak during January to February, albeit for a shorter period, and DE3 dominating the rest of the days, being much pronounced in June solstice. Similar results were also obtained by Pancheva and Mukhtarov (2012) by using F3/C electron density at $400 \mathrm{~km}$. The overall pattern of DE3 depicted in Fig. 5b could be related with their results, though the DE2 enhancement in December solstice months is absent here. Further, the annual variation of the relative amplitudes of DE2 and DE3 in the GIS results mostly agree with that shown by Chang et al. (2013b) using TEC values derived from multiyear F3/C measurements. Note that both the studies using F3/C measurements show DE2 enhancements during November to December and January months, particularly in $\mathrm{SH}$, which is absent in GIS. Further, there is a poleward shift in the peak DE2 latitude compared to DE3, which is particularly noticeable in the results of Chang et al. (2013b). However, the peak latitudes do not seem to differ in the GIS analysis. In addition to such morphological differences, the GIS results detail the signatures of daily tidal oscillations, which could not be inferred from the earlier multi-day averaged observations. On a day-to-day basis, the amplitudes vary in the range $5-30 \%$ of the zonal mean density. Moreover, the North and South peaks of the DE2 and DE3 amplitudes are better distinguishable in GIS results.

Considering the day-to-day differences in the amplitudes of tidal oscillations as described above, the net contribution of the non-migrating components in manifesting as daily variations of wave- 3 or wave- 4 modulations are further examined in Fig. 6. The non-migrating tides that mainly contribute to wave-3 (wave-4) structures are DE2 (DE3), stationary planetary wavenumber-3 or SPW3 (stationary planetary wavenumber-4 or SPW4) and semi-diurnal eastward propagating wavenumber-1 or SE1 (semi-diurnal eastward propagating wavenumber-2 or SE2) modes (Hagan et al. 2007; Forbes et al. 2008; Pancheva and Mukhtarov 2010; Chang et al. 2013b). Figure 6 gives the daily variations of their magnitudes as well as their net contribution at $1400 \mathrm{LT}$ when the wave- 4 feature is more prominent. Note that while wave- 3 and wave- 4 are global structures, the associated amplitudes do vary over different longitudes and on different days (Fig. 1). Figure 6, which shows the magnitudes at the selected longitude of $90^{\circ} \mathrm{E}$, demonstrates that the modulations are also subject to complex patterns of daily variations.

It can be seen from Fig. 6 that DE2 (DE3) and SPW3 (SPW4) magnitudes are more or less comparable, exhibiting mostly identical daily variations. However, the SE1 (SE2) magnitudes, which are about 50\% smaller, do not closely reflect these daily variations. Further the wave-3 (WN3) components depict more random daily variations than the wave-4 (WN4) counterparts and seem to influence the overall annual pattern of the net amplitude more. The combined effect of wave- 3 and wave-4 magnitudes (WN3 + WN4) suggest that the modulation maybe weaker or absent over this longitude during October to December. The daily variations of these modulations meant that on a given day, depending on which mode dominates, either a wave- 3 or wave-4, or more complex modulations of EIA density could exist in the fixed local-time longitudinal frame.

\section{DISCUSSIONS}

By effectively taking the advantages of the spacebased F7/C2 slant TECs and ground-based GNSS TEC (Lin et al. 2017), the GIS measurements described here offer a quantitative perception of the otherwise intractable 

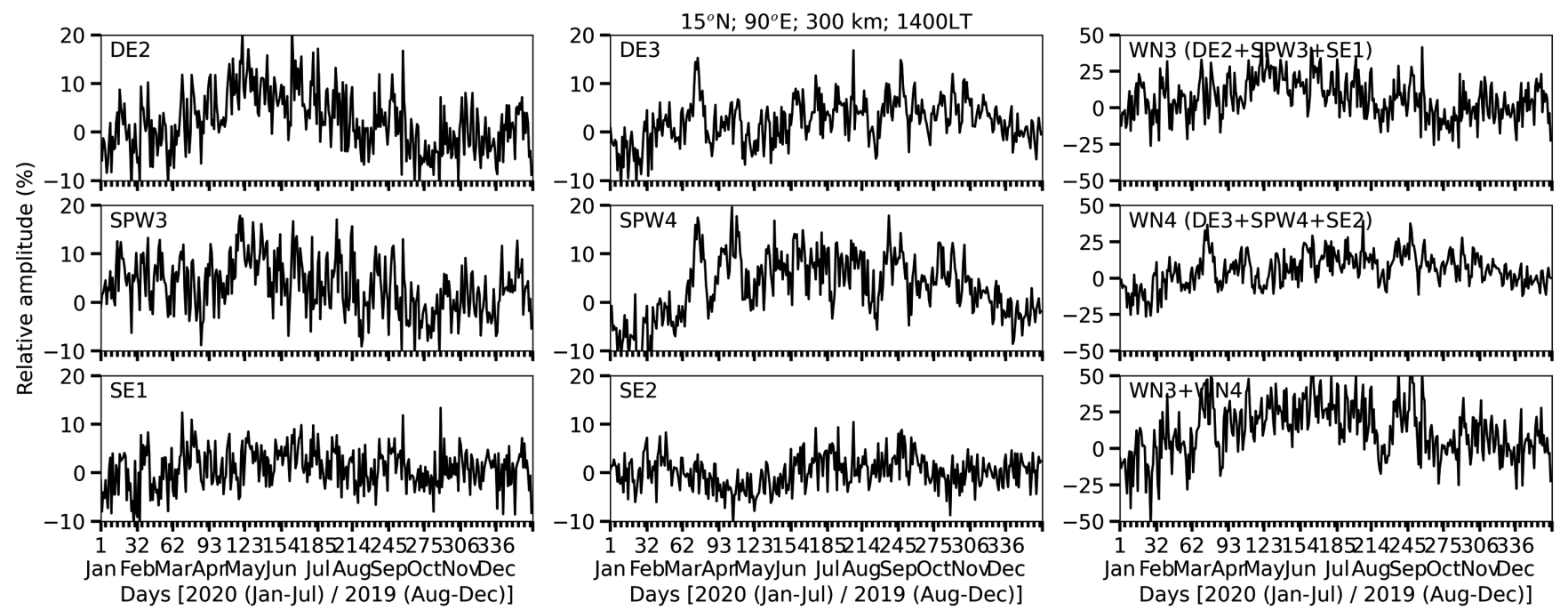

Fig. 6. Day-to-day variations of non-migrating magnitudes at $1400 \mathrm{LT}, 15^{\circ} \mathrm{N}$ magnetic latitude, and $300 \mathrm{~km}$ altitude during $2019-2020 \mathrm{over} 90^{\circ} \mathrm{E}$ longitude. (Left) The daily relative magnitudes of (top to bottom) DE2, SPW3, and SE1 oscillations that contribute to wave-3 (WN3) modulation, (middle) the relative amplitudes of (top to bottom) DE3, SPW4, and SE2 that give rise to wave-4 (WN4) pattern and (right) the combined amplitudes of (top to bottom) WN3, WN4, and their net (WN3+WN4) modulation.

daily variations of the global electron density distribution. The results during solar minimum reveal day-to-day electron density variations having an overall deviation in the range $15-30 \%$ over the EIA latitudes at $1400 \mathrm{LT}$ when the low-latitude density usually maximizes (Figs. 2 and 3). Earlier studies of day-to-day variability over mid-latitudes showed about $25-30 \%$ deviation in the F-peak electron density and TEC with respect to the monthly mean value during geomagnetically disturbed conditions (Mendillo et al. 1972). Rishbeth and Mendillo (2001) carried out a more comprehensive examination of the day-to-day variability, though over a limited number of ionosonde stations. The latitude, local-time, and seasonal characteristic of the variability revealed by GIS in general agree with those given by Rishbeth and Mendillo (2001). However, over a lowlatitude station, they reported about $12-25 \%$ average daytime standard deviation and $35-50 \%$ during nighttime. The GIS results (for a similar location) gives about $25-50 \%$ deviation in the nighttime (not shown), while the daytime variability is slightly larger in the range $15-45 \%$.

Note that the results of Rishbeth and Mendillo (2001) include mostly higher solar active period with more electron density than considered here. The percentage deviation yields larger values when the electron density is smaller. Moreover, the earlier studies were focused on the F-peak density, whereas the current study examines the density at a fixed altitude, which is expected to display larger dynamical variability, especially during day. Hence, it may be argued that the standard deviations reported here indeed would have been relatively lower if the solar activities were higher. Liu et al. (2013) noted that the standard deviations in their TIMEGCM simulations during January to February months under quiet geomagnetic conditions $(\sim 10 \%)$ was only half of that reported by Rishbeth and Mendillo (2001), attributing the resulting variability to arise mostly from meteorological sources. Their simulations were for a similar solar activity condition as during the current period of study. Though not shown here, the corresponding standard deviation in the GIS results was about $13-15 \%$. Furthermore, a comparison of the percentage standard deviation at $1600 \mathrm{LT}$ over low latitudes in their results (their Fig. 4b) with the corresponding GIS results (not shown) yielded approximately similar values (23 and 26\%, respectively).

Based on the above comparisons, the day-to-day variability in the GIS results reported here may be mostly of meteorological origin. There is no one-to-one correspondence between the day-to-day variations in electron density and the $\mathrm{f} 10.7 \mathrm{~cm}$ solar flux (Fig. 3), which is regarded as a good indicator of Solar UV and EUV variations. Note that the standard deviation of f10.7 variability with respect to monthly mean values is about $5 \%$ for solar minimum conditions (Rishbeth and Mendillo 2001) and it is mostly within $3 \%$ during the current period. Thus, coupling from lower atmospheric sources including possible non-linear tidal interactions become major driving factors for the day-to-day variations (Forbes et al. 2000; Liu et al. 2013). This is further signified by the deep solar minimum conditions that prevailed during the period of study, which also by far remained geomagnetically quiet (with Kp mostly below 4), except for a few weak-to-moderate disruptions (Fig. 3) and makes the period of study suitable for inferring the lowlatitude contributions with least influence from magnetic activity. Further, the daily variations of the tidal oscillations reported here (Figs. 4 - 6) indeed reflect similar variations 
in the electron density over the EIA crest(s) (Fig. 3), indicating that the observed density variations are related to lower atmospheric wave coupling.

The variability in the lower atmospheric forcing could arise from the day-to-day differences in the factors that influence the generation of the tides and waves such as planetary waves and gravity waves, changes in their morphology during their coupling and propagation to the upper atmosphere, and the result of complex non-linear interactions of the waves and tides that give rise to secondary waves or child waves (Forbes et al. 2008; Goncharenko et al. 2010, 2013; Liu et al. 2013; Pedatella and Liu 2013; Oberheide et al. 2015; Pedatella and Maute 2015; Sassi et al. 2021). The daily amplitudes of migrating and non-migrating electron density oscillations described here in general agree with the average pattern reported in the earlier studies, while also revealing dissimilarities. The disparities could be related to the differences in the daily characteristics of the tidal modes that force such oscillations in electron density, their propagation through background atmosphere, and possible interactions with other tidal modes and other waves. Note that the earlier studies combined about 45 - 60 days of F3/C observations to retrieve the tidal responses. Compared to the multi-day average analysis employed in such previous studies the current study benefits from the availability of daily GIS data, thereby more realistically reflecting the dayto-day changes in the electron density. The advantages of the daily measurements in revealing the latitudinal structure and seasonal characteristics of different tidal signatures in ionosphere and thus influencing the observed daily electron density distribution are further discussed below.

Among the ionospheric components of the migrating modes, the amplitudes of DW1 and SW2 responses extracted from GIS data are largest over the EIA crest latitudes, forcing some of the daily as well as multi-day variability in the crest electron density, with the former also influencing the observed seasonal distribution compared to the latter (Fig. 4). Even though the observed seasonal distribution of the daily amplitudes of these components in general agree with the earlier analyzes by using F3/C electron density profiles (Pancheva and Mukhtarov 2012; Chang et al. 2013a), such studies could not resolve distinct $\mathrm{NH}$ and SH EIA peaks in the DW1 electron density oscillations as seen in the GIS results. Pancheva et al. (2012) reported a similar DW1 "splitting" with respect to the equator in their GAIA (Ground-to-topside model of Atmosphere and Ionosphere for Aeronomy) simulations, which they attributed to the latitudinal structure and strength of the simulated SW2 tide amplitudes. The DW1 "splitting" weakened when the SW2 tide was diminished and yielded mostly an equatorial peak as in their $\mathrm{F} 3 / \mathrm{C}$ observations in the absence of the forcing. While such variations in the SW2 tidal forcing would influence the latitudinal structure of the ionospheric DW1 as explained by Pancheva et al. (2012), the manifestation as a single equatorial peak in the earlier studies could partly be an artifact of the 45 - 60 days of moving window used to accumulate the F3/C measurements. The rationale for this argument is that, when a much smaller (20-days) moving window was used by Lin et al. (2012) to examine the tidal oscillations in electron density during the 2009 SSW period, their DW1 amplitudes seemed to resolve very weak $\mathrm{NH}$ and SH crests. Further, when they re-examined the same 2009 event using daily GIS electron density (Lin et al. 2019), distinct $\mathrm{NH}$ and $\mathrm{SH}$ peaks were evident in their DW1 results.

Thus, when multi-day averaging is employed, the daily variations of the EIA structures would yield a smoother distribution and the resulting amplitudes may fail to capture the true latitudinal DW1 response. However, the daily DW1 amplitudes in TEC over 200 - $800 \mathrm{~km}$ derived from Thermosphere-Ionosphere-Electrodynamics General Circulation Model (TIE-GCM) simulations by Chang et al. (2013a) showed mostly an equatorial peak as in the F3/C observations, apparently contradicting this argument. There could be two factors that might have contributed to this discrepancy. First maybe that the $5^{\circ}$ latitudinal grid they used resulted in a smoothened latitudinal variation. Second, they used monthly GSWM (Global Scale Wave Model) climatology to specify the tidal forcing at their model lower boundary, which would have effectively generated a similar average response. It should also be mentioned that the SW2 ionospheric signatures in the same earlier studies resolved the North and South peaks despite the same multi-day averaging. This maybe because, in contrast to DW1, the SW2 oscillations in electron density are mostly limited to the EIA latitudes, being much weaker or absent over the equator to be affected by the averaging (Fig. 4).

By utilizing the daily global observations, the GIS results thus demonstrate strong DW1 modulation of the EIA crests. Pancheva and Mukhtarov (2012) attributed the DW1 response in the $\mathrm{F} 3 / \mathrm{C}$ electron density to be mostly forced by variations in photoionization related to solar zenith angle. Chang et al. (2013a) compared the F3/C observations with TIE-GCM simulations and made similar conclusions, highlighting the role of DW1 in contributing to the equatorial plasma density. Though no direct evidence could be ascertained about the origin of the observed DW1 variability from the GIS density, a comparison with the previous TIE-GCM simulations of migrating tides by Chang et al. (2013a) indicates that the seasonal distribution of the amplitudes retrieved from GIS (Fig. 4) agree closely with the model run with DW1 lower atmospheric forcing turned off. While this correspondence does indicate in situ DW1 forcing through photoionization, there could be significant inter-annual variability in the tide distributions, and hence the above comparison of the annual pattern with the model simulation would require further observations to confirm.

Considering that most of the observed DW1 response is in situ forced through photoionization, it is expected to 
contribute to the equatorial electron density (Pancheva and Mukhtarov 2012; Chang et al. 2013a), unlike the peaks in the GIS results over the EIA latitudes. However, SW2 has been regarded to mainly modulate the daytime vertical plasma drifts, with the diurnal component having little effect (for e.g., Millward et al. 2001; Chang et al. 2013a; Fang et al. 2013). The dependence of "DW1 splitting" on the SW2 lower atmospheric forcing mentioned earlier (Pancheva et al. 2012), thus indicate the role of SW2 drifts in re-distributing the equatorial ionization. Another possibility is a positive feedback to the DW1 oscillations in electron density or drift through multiplicative interaction between the zonal mean electron density and the DW1 electric fields as suggested by Chang et al. (2013a). The photoionization and recombination are modulated by the diurnal variations of solar insolation, and neutral and plasma densities, influencing the zonal mean electron density and the DW1 component. Also, note that DW1 variability of neutral temperature in the MLT region peaks near the geographic equator, whereas the peak in the zonal neutral wind is around $\pm 20^{\circ}$ latitudes (Forbes 1995; Hagan and Forbes 2002; Zhang et al. 2010). Thus, any associated DW1 variability in the meridional circulation could also modulate to the electron density distribution over the EIA latitudes.

Unlike DW1, the latitudinal and seasonal distributions of SW2 and TW3 oscillations appear more straightforward to interpret. The agreement in the seasonal distributions of GIS electron density and the retrieved migrating oscillations with the previous simulation results (Pancheva et al. 2012; Chang et al. 2013a) suggests that the observed SW2 responses are forced from the lower atmosphere. The TW3 amplitudes exhibit more random daily variations and appear mostly over the equator, indicating that direct solar forcing may be contributing rather than dynamo modulations. The weaker secondary TW3 peaks over the EIA latitudes at F-region heights might indicate their in-situ generation by nonlinear interactions between DW1 and SW2 (Chang et al. 2013a).

Similar to the migrating tides, the major non-migrating tides described here also exhibit significant daily variations, indicating corresponding day-to-day variations of their sources. Note that the relative amplitudes of DE2 and DE3 are consistently stronger in the SH compared to $\mathrm{NH}$. Though the diurnal variations of warming during day and subsequent nighttime cooling is more effective over land regions, convective systems and associated variations in latent heat release would be frequent over ocean, giving rise to the stronger SH amplitudes. The daily variations of the amplitudes of non-migrating tides further signify their relative contribution in manifesting as wave- 3 of wave-4 longitudinal structure. Using F3/C TEC, Chang et al. (2013b) noted stronger wave-4 variability of EIA compared to wave-3 contribution. The GIS results reveal that wave- 3 amplitudes slightly dominate the net contribution to the longitudinal
EIA modulation (Fig. 6). Such differences might be the result of inter-annual variability in the tidal forcing (Forbes et al. 2008), which thus makes the study of day-to-day variability more complex.

To quantify the contributions of in situ forced variations and the oscillations in response to tidal forcing from below to the observed day-to-day electron density variations, the reconstructed electron density from the combinations of different tidal components at a given longitude and time are further examined in Fig. 7. The background zonal and diurnal mean (Fig. 7b) and the in situ DW1 oscillations (Fig. 7c) exhibit mostly identical daily variations of much smaller amplitudes. Taken together, they account for only part of the daily variations, adding about $10-25 \%$ variability with respect to the average electron density. However, together they constitute about $75-90 \%$ of the observed electron density. On the other hand, Fig. $7 d$ shows that the net contribution to the observed electron density by SW2, and the non-migrating DE2, DE3, SPW3, SPW4, SE1, and SE2 components, which originate in the lower atmosphere and considered to greatly influence the ionospheric dynamics, is only $10-15 \%$ on most of the days. Nevertheless, the lower atmospheric forcing through these components give rise to another 5 - 20\% daily fluctuations in the average electron density, which is almost identical to that from the background variations and in situ forcing.

Thus, in-situ forcing has almost an equal impact as the lower atmospheric forcing by SW2 and the non-migrating DE2, DE3, SPW3, SPW4, SE1, and SE2 components in producing the day-to-day variability, each yielding about $5-25 \%$ of the deviations. Taken together, the background, in-situ and the above mentioned lower atmospheric contributions (Fig. 7e) do not sum up to match the observed day-to-day variability. The forcing from the residual tidal oscillations, which includes all the tide modes used in the decomposition in this study, excluding DW1, SW2, TW3, DE2, DE3, SPW3, SPW4, SE1, SE2 modes (Fig. 7f) thus plays a significant role, imparting almost $50 \%$ of the observed electron density variations. Considering that these residual variations are also coupled from the lower atmosphere, it can be concluded from the tidal decomposition of the GIS electron density that about $75 \%$ of the observed day-to-day variability is of meteorological origin and in-situ forcing and background variations give rise to the rest. Note that the daily instantaneous amplitudes of the different tide modes shown here are also a manifestation of their phase variations, which is hence not separately examined here.

Though the contribution of non-migrating DE3, SPW3, SPW4, SE1, and SE2 tides is relatively negligible when examining the daily density values at a given longitude (Fig. 7), these tides are shown to be responsible for the longitudinal structuring of the EIA crests (Hagan et al. 2007; Lin et al. 2007; Forbes et al. 2008; Pancheva and Mukhtarov 2010, 2012; Chang et al. 2013b). Figure 8 


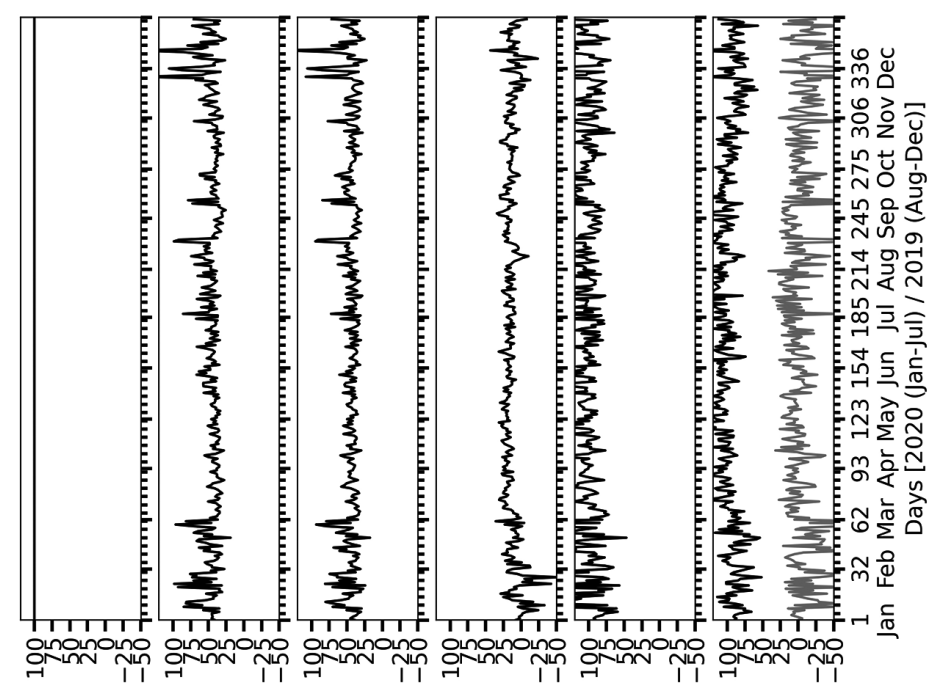

(\%) Kұ! suәp ןе707 to uo!plodold

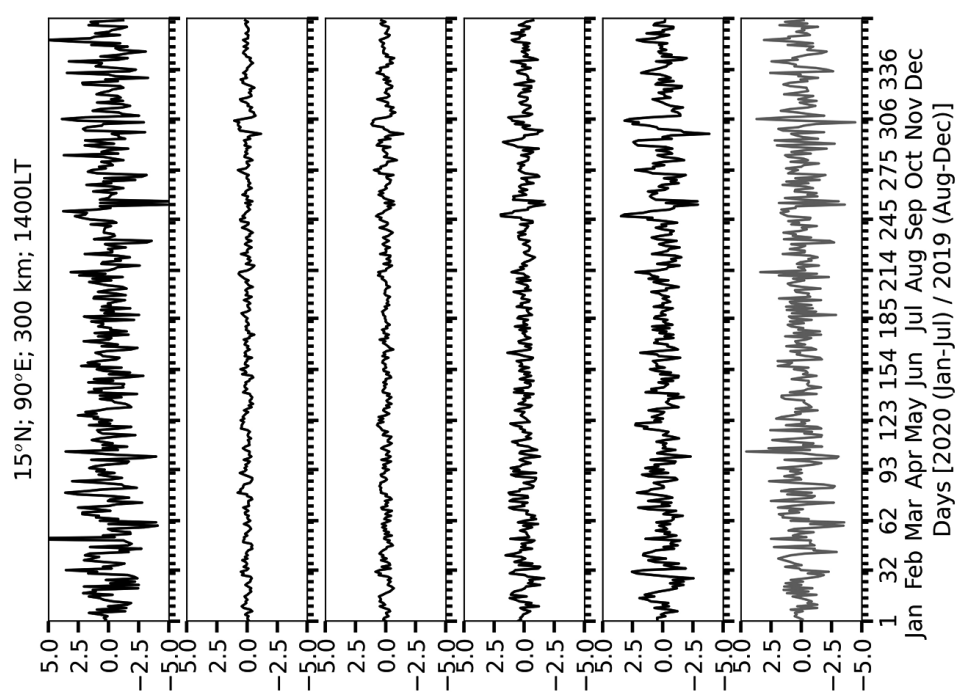

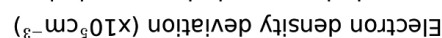

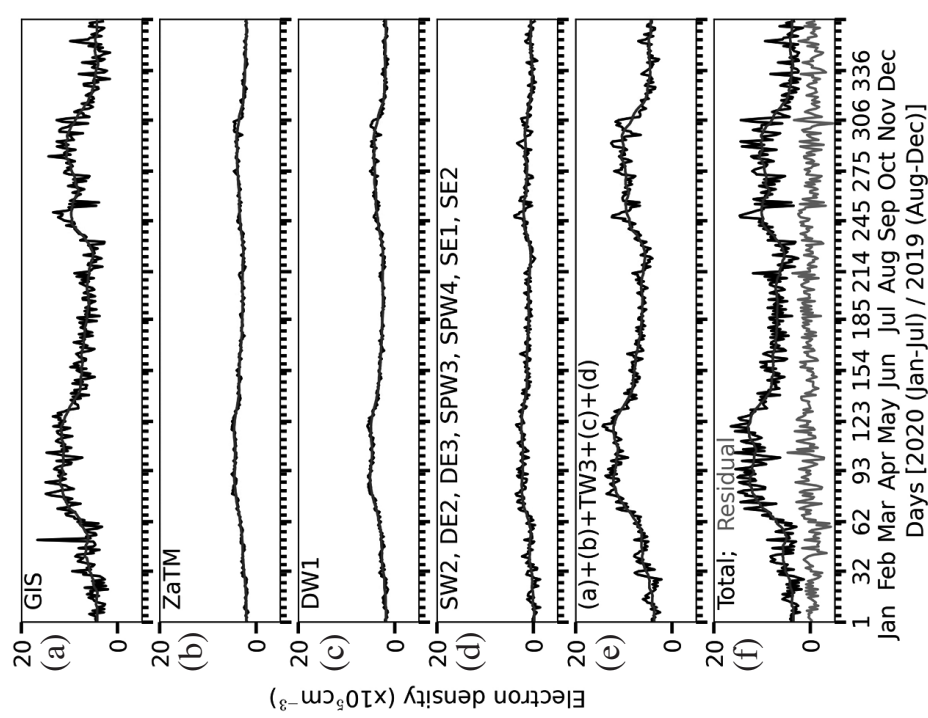

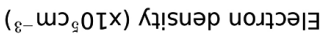

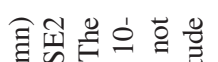

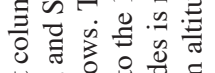

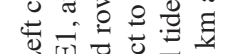
可跑

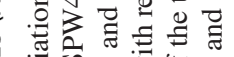
的范范

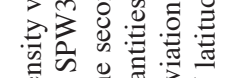
चल

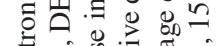

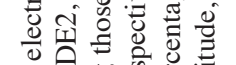
पते

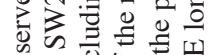

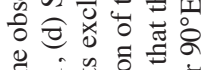

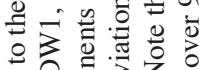
过实完

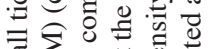
ส

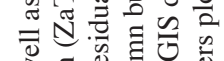

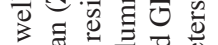
वे छ on 0 क

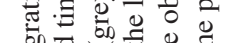

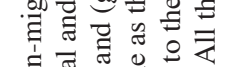

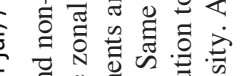

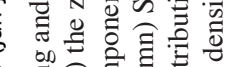

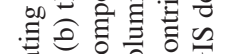
b.

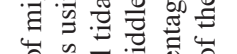

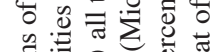

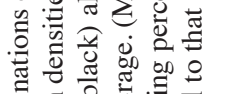
है 记

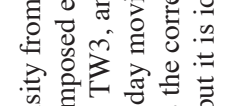

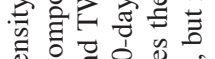

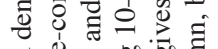
प्ठ்

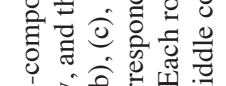

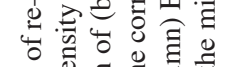

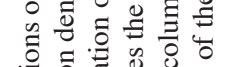

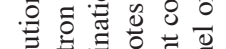

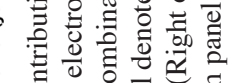

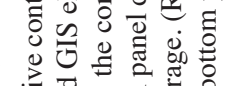
:

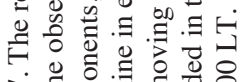

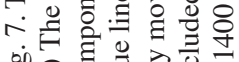

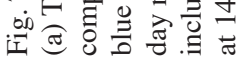



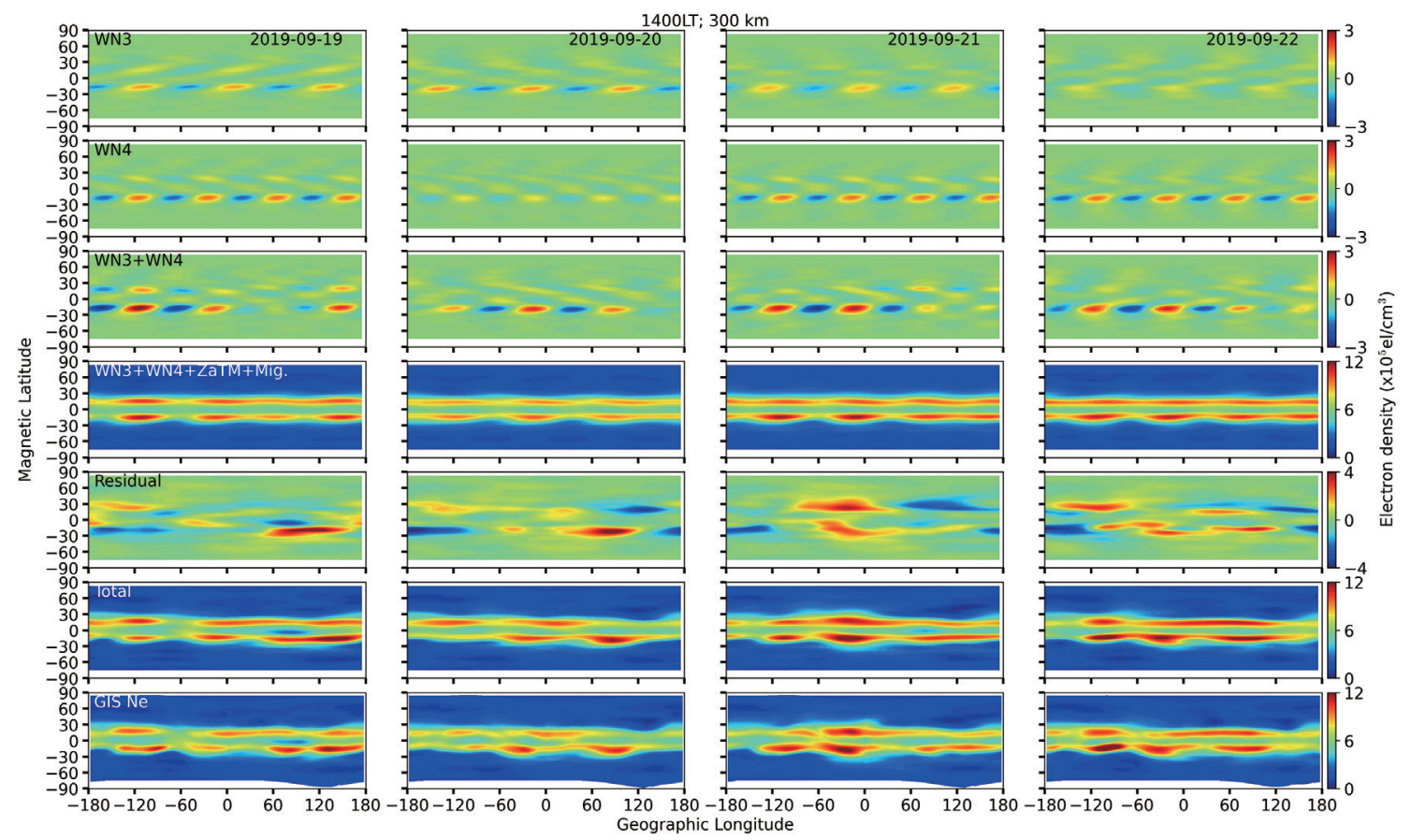

Fig. 8. Relative contribution of non-migrating tides in the longitudinal wave-3 or wave-4 structuring of EIA. (Top to bottom) The re-constructed density by using (row 1) DE2, SPW3, and SE1 tides (denoted by WN3), (row 2) DE3, SPW4 and SE2 tides (denoted by WN4), (row 3) combination of WN3 and WN4, (row 4) WN3, WN4, zonal and time mean (ZaTM) and migrating tides, (row 5) the residual tides that include the contribution of all the tide modes used in the decomposition in this study, excluding DW1, SW2, TW3, DE2, DE3, SPW3, SPW4, SE1, SE2 modes, (row 6) the total tides, and (row 7) the observed GIS density on (left to right) 19, 20,21, and 22 September 2019 over $300 \mathrm{~km}$ altitude at $1400 \mathrm{LT}$.

demonstrates how the daily WN3 and WN4 tides, as well as their net amplitudes modulate the corresponding longitudinal EIA structure during the consecutive days of 19 to 22 September 2019. Though the GIS density on all these four days showed pronounced wave-4 signature, there are also notable day-to-day differences (Fig. 1). It can be seen from Fig. 8 that the reconstructed density on a given day may reveal a wave- 3 or a wave- 4 longitudinal pattern depending on the relative amplitudes and phases (longitudes of the respective peaks) of the WN3 and WN4 components at the given local time. To illustrate this point, except on 20 September (column 2), the WN4 amplitudes (row 2) are approximately identical to or more pronounced than the WN3 amplitudes (row 1). The net amplitude of the two (rows 3 and 4) is dominated by a wave-3 modulation on this day, whereas wave- 4 pattern is evident on all other days. Further, when the two contributions are of similar in strength but out of phase, the net amplitude may be reduced over that longitude sector (e.g., the diminished peak over $60^{\circ} \mathrm{E}$ on 19 September in rows 3 and 4). In other words, peaks of the resulting modulation on a given day would also depend on whether these modes superimpose coherently or not. A similar influence of the phase variations of wave-3 and wave- 4 components in producing day-to-day variability of TEC measurements and the longitudinal wave structure through constructive or destructive interference was discussed by McDonald et al. (2018).
However, Fig. 8 shows that the EIA modulation on a given day could not be simply related to the combination of the WN3 and WN4 components, and the observed density distribution could exhibit a different longitudinal pattern (row 7) even after including the contribution of the migrating tides and the zonal mean (row 4). There are also notable hemispheric differences in the observed longitudinal structure when compared to the modulations by the combination of WN3 and WN4. Thus, as noted above, the residual tides also influence the observed density pattern. This could be verified by the longitudinal distribution of the residual tides (row 5) on these days and comparing the re-constructed density by including all the tides (row 6) with the observation. When the residual tides are included, the re-constructed density more-or-less resembles the observed pattern.

The results thus demonstrate that, while the net contribution of WN3 and WN4 components yields a wave-3 or wave- 4 modulation of the EIA crests as reported in the earlier studies, the day-to-day variations of the net longitudinal structure, including the density as well as location (longitude) of the peaks, and the hemispheric asymmetry, also depends on the daily distributions of the residual components. The results further explain the discrepancy noted by Lin et al. (2007) in the eastward propagation speeds of the wave-4 peaks with the theoretical phase velocity of DE3 tides, because the residual tides influence the observed peak locations. Note that there are still minor differences 
between the observation (row 7) and the total retrieved density (row 6), which may be resolved if the contributions from higher wave numbers, secondary waves through nonlinear interactions and other planetary waves are included in the tidal decomposition.

\section{SUMMARY}

The GIS electron density maps derived from F7/C2 measurements show that the day-to-day variability of lowlatitude electron density during daytime amounts to about $10-20 \%$ standard deviation in equinoxes, $20-30 \%$ in solstices, becoming as large as $40-50 \%$ in winter. The percentage deviation is larger during nighttime, reaching up to about $30-60 \%$, with largest standard deviations in the solstices. Over EIA latitude the day-to-day variability at 1400 LT is in the range $15-30 \%$. The tidal decomposition of the GIS electron density reveals that about $75 \%$ of the observed day-to-day variability is of meteorological origin and insitu forcing and background variations give rise to the rest. Note that these observations are carried out during a period of deep solar minimum conditions, which was mostly geomagnetically quiet except for some minor disturbances. The conditions were mostly identical to those used in the simulations of Liu et al. (2013), though their study could totally exclude any influence of magnetic disturbances. The results further reveal strong DW1 response over the EIA crest latitudes, whereas earlier studies using multi-day averaging showed DW1 amplitudes to maximize over the equator. Though the non-migrating DE2, DE3, SPW3, SPW4, SE1, and SE2 components contribute negligibly to the daily electron density, they induce significant day-to-day variations in the wave- 3 or wave- 4 longitudinal structures depending on their relative amplitude and maxima longitudes in a fixed local-time frame. The results demonstrate that the day-to-day variation and the longitudinal modulation could not be simply related to these non-migrating and migrating components alone, and roles of the residual tides including higher wave numbers, secondary waves through non-linear interactions, and other planetary waves are also important in modifying the EIA crests.

\section{DATA AVAILABILITY STATEMENT}

The Global Ionospheric Specification (GIS) electron density data used in this study are available online at the National Cheng Kung University web-platform for providing FORMOST-7/COSMIC-2 (F7/C2) ionospheric data products (http://formosat7.earth.ncku.edu.tw). The data access is granted only through a log-in process as per the institutional regulations. A free user account could be created by signingup by providing some basic information including name and a valid email address at http://formosat7.earth.ncku.edu.tw/ join.php. After logging-in with the account, the GIS data could be selected for the desired period among other F7/C2 data products that are available from the Downloads menu.

Acknowledgements This work is supported by the Ministry of Science and Technology (MOST), Taiwan under project MOST 108-2638-M-006-001-MY2 and part of the work is supported by National Space Organization (NSPO) under project NSPO-S-108004. TM is supported by the National Science Foundation (NSF) AGS-1651469 and AGS-1848544 awards. The authors acknowledge the space weather data services of Natural Resources Canada (https:// www.spaceweather.gc.ca/solarflux/sx-en.php) for hosting the $\mathrm{f} 10.7 \mathrm{~cm}$ solar flux measurements made at Dominion Radio Astrophysical Observatory (DRAO), Penticton, and the Space Physics Data Facility (SPDF) for the Kp magnetic index (https://omniweb.gsfc.nasa.gov).

\section{REFERENCES}

Anderson, D. N., 1973: A theoretical study of the ionospheric $\mathrm{F}$ region equatorial anomaly-I. Theory. Planet. Space Sci., 21, 409-419, doi: 10.1016/00320633(73)90040-8. [Link]

Appleton, E. V., 1946: Two Anomalies in the Ionosphere. Nature, 157, 691, doi: 10.1038/157691a0. [Link]

Bauer, S. J., 1958: Correlations between tropospheric and ionospheric parameters. Geofisica Pura e Applicata, 40, 235-240, doi: 10.1007/BF01980131. [Link]

Blanc, M. and A. D. Richmond, 1980: The ionospheric disturbance dynamo. J. Geophys. Res., 85, 1669-1686, doi: 10.1029/JA085iA04p01669. [Link]

Chang, L. C., C.-H. Lin, J.-Y. Liu, N. Balan, J. Yue, and J.-T. Lin, 2013a: Seasonal and local time variation of ionospheric migrating tides in 2007-2011 FORMOSAT-3/COSMIC and TIE-GCM total electron content. J. Geophys. Res., 118, 2545-2564, doi: 10.1002/ jgra.50268. [Link]

Chang, L. C., C.-H. Lin, J. Yue, J.-Y. Liu, and J.-T. Lin, 2013b: Stationary planetary wave and nonmigrating tidal signatures in ionospheric wave 3 and wave 4 variations in 2007-2011 FORMOSAT-3/COSMIC observations. J. Geophys. Res., 118, 6651-6665, doi: 10.1002/jgra.50583. [Link]

Chen, C. H., C. H. Lin, L. C. Chang, J. D. Huba, J. T. Lin, A. Saito, and J. Y. Liu, 2013: Thermospheric tidal effects on the ionospheric midlatitude summer nighttime anomaly using SAMI3 and TIEGCM. J. Geophys. Res., 118, 3836-3845, doi: 10.1002/jgra.50340. [Link]

England, S. L., T. J. Immel, E. Sagawa, S. B. Henderson, M. E. Hagan, S. B. Mende, H. U. Frey, C. M. Swenson, and L. J. Paxton, 2006: Effect of atmospheric tides on the morphology of the quiet time, postsunset equatorial ionospheric anomaly. J. Geophys. Res., 111, A10S19, doi: 10.1029/2006JA011795. [Link] 
England, S. L., T. J. Immel, J. D. Huba, M. E. Hagan, A. Maute, and R. DeMajistre, 2010: Modeling of multiple effects of atmospheric tides on the ionosphere: An examination of possible coupling mechanisms responsible for the longitudinal structure of the equatorial ionosphere. J. Geophys. Res., 115, A05308, doi: 10.1029/2009JA014894. [Link]

Fang, T.-W., H. Kil, G. Millward, A. D. Richmond, J.-Y. Liu, and S.-J. Oh, 2009: Causal link of the wave-4 structures in plasma density and vertical plasma drift in the low-latitude ionosphere. J. Geophys. Res., 114, A10315, doi: 10.1029/2009JA014460. [Link]

Fang, T.-W., R. Akmaev, T. Fuller-Rowell, F. Wu, N. Maruyama, and G. Millward, 2013: Longitudinal and day-to-day variability in the ionosphere from lower atmosphere tidal forcing. Geophys. Res. Lett., 40, 25232528, doi: 10.1002/grl.50550. [Link]

Fang, T.-W., T. Fuller-Rowell, V. Yudin, T. Matsuo, and R. Viereck, 2018: Quantifying the sources of ionosphere day-to-day variability. J. Geophys. Res., 123, 96829696, doi: 10.1029/2018JA025525. [Link]

Fejer, B. G., C. A. Gonzales, D. T. Farley, M. C. Kelley, and R. F. Woodman, 1979: Equatorial electric fields during magnetically disturbed conditions 1 . The effect of the interplanetary magnetic field. J. Geophys. Res., 84, 5797-5802, doi: 10.1029/JA084iA10p05797. [Link]

Fejer, J. A., 1964: Atmospheric tides and associated magnetic effects. Rev. Geophys., 2, 275-309, doi: 10.1029/ RG002i002p00275. [Link]

Forbes, J. M., 1995: Tidal and Planetary Waves. In: Johnson, R. M. and T. L. Killeen (Eds.), The Upper Mesosphere and Lower Thermosphere: A Review of Experiment and Theory, Volume 87, American Geophysical Union, doi: 10.1029/GM087p0067. [Link]

Forbes, J. M., S. E. Palo, and X. Zhang, 2000: Variability of the ionosphere. J. Atmos. Terr. Phys., 62, 685-693, doi: 10.1016/S1364-6826(00)00029-8. [Link]

Forbes, J. M., X. Zhang, E. R. Talaat, and W. Ward, 2003: Nonmigrating diurnal tides in the thermosphere. J. Geophys. Res., 108, 1033, doi: 10.1029/2002JA009262. [Link]

Forbes, J. M., X. Zhang, S. Palo, J. Russell, C. J. Mertens, and M. Mlynczak, 2008: Tidal variability in the ionospheric dynamo region. J. Geophys. Res., 113, A02310, doi: 10.1029/2007JA012737. [Link]

Forbes, J. M., X. Zhang, R. Heelis, R. Stoneback, C. R. Englert, J. M. Harlander, B. J. Harding, K. D. Marr, J. J. Makela, and T. J. Immel, 2021: Atmosphere-Ionosphere (A-I) coupling as viewed by ICON: Day-today variability due to planetary wave (PW)-tide interactions. J. Geophys. Res., 126, e2020JA028927, doi: 10.1029/2020JA028927. [Link]

Fraser, G. J. and M. R. Thorpe, 1976: Experimental investigations of ionospheric/stratospheric coupling in southern mid latitudes -1 . Spectra and cross-spectra of stratospheric temperatures and the ionospheric $f$-min parameter. J. Atmos. Terr. Phys., 38, 1003-1011, doi: 10.1016/0021-9169(76)90083-0. [Link]

Goncharenko, L. P., A. J. Coster, J. L. Chau, and C. E. Valladares, 2010: Impact of sudden stratospheric warmings on equatorial ionization anomaly. J. Geophys. Res., 115, A00G07, doi: 10.1029/2010JA015400. [Link]

Goncharenko, L. P., J. L. Chau, P. Condor, A. Coster, and L. Benkevitch, 2013: Ionospheric effects of sudden stratospheric warming during moderate-to-high solar activity: Case study of January 2013. Geophys. Res. Lett., 40, 4982-4986, doi: 10.1002/grl.50980. [Link]

Gonzales, C. A., M. C. Kelley, B. G. Fejer, J. F. Vickrey, and R. F. Woodman, 1979: Equatorial electric fields during magnetically disturbed conditions 2 . Implications of simultaneous auroral and equatorial measurements. J. Geophys. Res., 84, 5803-5812, doi: 10.1029/ JA084iA10p05803. [Link]

Hagan, M. E. and J. M. Forbes, 2002: Migrating and nonmigrating diurnal tides in the middle and upper atmosphere excited by tropospheric latent heat release. J. Geophys. Res., 107, 4754, doi: 10.1029/2001JD001236. [Link]

Hagan, M. E. and J. M. Forbes, 2003: Migrating and nonmigrating semidiurnal tides in the upper atmosphere excited by tropospheric latent heat release. J. Geophys. Res., 108, 1062, doi: 10.1029/2002JA009466. [Link]

Hagan, M. E., J. L. Chang, and S. K. Avery, 1997: Global-scale wave model estimates of nonmigrating tidal effects. J. Geophys. Res., 102, 16439-16452, doi: 10.1029/97JD01269. [Link]

Hagan, M. E., A. Maute, R. G. Roble, A. D. Richmond, T. J. Immel, and S. L. England, 2007: Connections between deep tropical clouds and the Earth's ionosphere. Geophys. Res. Lett., 34, L20109, doi: 10.1029/2007GL030142. [Link]

Huang, C.-S., 2019: Long-lasting penetration electric fields during geomagnetic storms: Observations and mechanisms. J. Geophys. Res., 124, 9640-9664, doi: 10.1029/2019JA026793. [Link]

Immel, T. J., E. Sagawa, S. L. England, S. B. Henderson, M. E. Hagan, S. B. Mende, H. U. Frey, C. M. Swenson, and L. J. Paxton, 2006: Control of equatorial ionospheric morphology by atmospheric tides. Geophys. Res. Lett., 33, L15108, doi: 10.1029/2006GL026161. [Link]

Kazimirovsky, E. S. and V. D. Kokourov, 1991: The Tropospheric and Stratospheric Effects in the Ionosphere. J. Geomagn. Geoelectr., 43, 551-562, doi: 10.5636/ jgg.43.supplement1_551. [Link]

Lean, J. L., R. R. Meier, J. M. Picone, F. Sassi, J. T. Emmert, and P. G. Richards, 2016: Ionospheric total electron content: Spatial patterns of variability. J. Geophys. 
Res., 121, 10367-10402, doi: 10.1002/2016JA023210. [Link]

Lin, C. H., A. D. Richmond, J. Y. Liu, H. C. Yeh, L. J. Paxton, G. Lu, H. F. Tsai, and S.-Y. Su, 2005a: Largescale variations of the low-latitude ionosphere during the October-November 2003 superstorm: Observational results. J. Geophys. Res., 110, A09S28, doi: 10.1029/2004JA010900. [Link]

Lin, C. H., A. D. Richmond, R. A. Heelis, G. J. Bailey, G. Lu, J. Y. Liu, H. C. Yeh, and S.-Y. Su, 2005b: Theoretical study of the low- and midlatitude ionospheric electron density enhancement during the October 2003 superstorm: Relative importance of the neutral wind and the electric field. J. Geophys. Res., 110, A12312, doi: 10.1029/2005JA011304. [Link]

Lin, C. H., C. C. Hsiao, J. Y. Liu, and C. H. Liu, 2007: Longitudinal structure of the equatorial ionosphere: Time evolution of the four-peaked EIA structure. J. Geophys. Res., 112, A12305, doi: 10.1029/2007JA012455. [Link]

Lin, C.-Y., T. Matsuo, J. Y. Liu, C. H. Lin, J. D. Huba, H. F. Tsai, and C. Y. Chen, 2017: Data assimilation of ground-based GPS and radio occultation total electron content for global ionospheric specification. J. Geophys. Res., 122, 10876-10886, doi: 10.1002/2017JA024185. [Link]

Lin, C.-Y., C. C.-H. Lin, J.-Y. Liu, P. K. Rajesh, T. Matsuo, M.-Y. Chou, H.-F. Tsai, and W.-H. Yeh, 2020a: The early results and validation of FORMOSAT-7/COSMIC-2 space weather products: Global ionospheric specification and Ne-aided Abel electron density profile. J. Geophys. Res., 125, e2020JA028028, doi: 10.1029/2020JA028028. [Link]

Lin, J. T., C. H. Lin, L. C. Chang, H. H. Huang, J. Y. Liu, A. B. Chen, C. H. Chen, and C. H. Liu, 2012: Observational evidence of ionospheric migrating tide modification during the 2009 stratospheric sudden warming. Geophys. Res. Lett., 39, L02101, doi: 10.1029/2011GL050248. [Link]

Lin, J. T., C. H. Lin, C. Y. Lin, N. M. Pedatella, P. K. Rajesh, T. Matsuo, and J. Y. Liu, 2019: Revisiting the modulations of ionospheric solar and lunar migrating tides during the 2009 stratospheric sudden warming by using global ionosphere specification. Space Weather, 17, 767-777, doi: 10.1029/2019SW002184. [Link]

Lin, J. T., C. H. Lin, P. K. Rajesh, J. Yue, C. Y. Lin, and T. Matsuo, 2020b: Local-Time and Vertical Characteristics of Quasi-6-Day Oscillation in the Ionosphere during the 2019 Antarctic Sudden Stratospheric Warming. Geophys. Res. Lett., 47, e2020GL090345, doi: 10.1029/2020GL090345. [Link]

Lindzen, R. S., 1979: Atmospheric Tides. Аnnu. Rev. Earth Planet. Sci., 7, 199-225, doi: 10.1146/annurev. ea.07.050179.001215. [Link]
Liu, H.-L., V. A. Yudin, and R. G. Roble, 2013: Day-today ionospheric variability due to lower atmosphere perturbations. Geophys. Res. Lett., 40, 665-670, doi: 10.1002/grl.50125. [Link]

Martyn,D. F., 1947: Atmospheric tides in the ionosphere - I. Solar tides in the $F_{2}$ region. Proc. R. Soc. London Ser. A-Math. Phys. Eng. Sci., 189, 241-260, doi: 10.1098/ rspa.1947.0037. [Link]

McDonald, S. E., F. Sassi, J. Tate, J. McCormack, D. D. Kuhl, D. P. Drob, C. Metzler, and A. J. Mannucci, 2018: Impact of non-migrating tides on the low latitude ionosphere during a sudden stratospheric warming event in January 2010. J. Atmos. Sol.-Terr. Phys., 171, 188-200, doi: 10.1016/j.jastp.2017.09.012. [Link]

Mendillo, M., M. D. Papagiannis, and J. A. Klobuchar, 1972: Average behavior of the midlatitude $F$-region parameters $N_{T}, N_{\max }$, and $\tau$ during geomagnetic storms. J. Geophys. Res., 77, 4891-4895, doi: 10.1029/ JA077i025p04891. [Link]

Millward, G. H., I. C. F. Müller-Wodarg, A. D. Aylward, T. J. Fuller-Rowell, A. D. Richmond, and R. J. Moffett, 2001: An investigation into the influence of tidal forcing on $\mathrm{F}$ region equatorial vertical ion drift using a global ionosphere-thermosphere model with coupled electrodynamics. J. Geophys. Res., 106, 24733-24744, doi: 10.1029/2000JA000342. [Link]

Oberheide, J., K. Shiokawa, S. Gurubaran, W. E. Ward, H. Fujiwara, M. J. Kosch, J. J. Makela, and H. Takahashi, 2015: The geospace response to variable inputs from the lower atmosphere: A review of the progress made by Task Group 4 of CAWSES-II. Prog. Earth Planet. Sci., 2, 2, doi: 10.1186/s40645-014-0031-4. [Link]

Pancheva, D. and P. Mukhtarov, 2010: Strong evidence for the tidal control on the longitudinal structure of the ionospheric F-region. Geophys. Res. Lett., 37, L14105, doi: 10.1029/2010GL044039. [Link]

Pancheva, D. and P. Mukhtarov, 2012: Global Response of the Ionosphere to Atmospheric Tides Forced from Below: Recent Progress Based on Satellite Measurements. Space Sci. Rev., 168, 175-209, doi: 10.1007/ s11214-011-9837-1. [Link]

Pancheva, D., Y. Miyoshi, P. Mukhtarov, H. Jin, H. Shinagawa, and H. Fujiwara, 2012: Global response of the ionosphere to atmospheric tides forced from below: Comparison between COSMIC measurements and simulations by atmosphere-ionosphere coupled model GAIA. J. Geophys. Res., 117, A07319, doi: 10.1029/2011JA017452. [Link]

Pedatella, N. M. and J. M. Forbes, 2010: Evidence for stratosphere sudden warming-ionosphere coupling due to vertically propagating tides. Geophys. Res. Lett., 37, L11104, doi: 10.1029/2010GL043560. [Link]

Pedatella, N. M. and H.-L. Liu, 2013: The influence of atmospheric tide and planetary wave variability during 
sudden stratosphere warmings on the low latitude ionosphere.J. Geophys. Res., 118, 5333-5347, doi: 10.1002/ jgra.50492. [Link]

Pedatella, N. M. and A. Maute, 2015: Impact of the semidiurnal lunar tide on the midlatitude thermospheric wind and ionosphere during sudden stratosphere warmings. J. Geophys. Res., 120, 10740-10753, doi: 10.1002/2015JA021986. [Link]

Pedatella, N. M., M. E. Hagan, and A. Maute, 2012: The comparative importance of DE3, SE2, and SPW4 on the generation of wavenumber-4 longitude structures in the low-latitude ionosphere during September equinox. Geophys. Res. Lett., 39, L19108, doi: 10.1029/2012GL053643. [Link]

Pedatella, N. M., J. Oberheide, E. K. Sutton, H.-L. Liu, J. L. Anderson, and K. Raeder, 2016: Short-term nonmigrating tide variability in the mesosphere, thermosphere, and ionosphere. J. Geophys. Res., 121, 36213633, doi: 10.1002/2016JA022528. [Link]

Prölss, G. W., 1993: Common origin of positive ionospheric storms at middle latitudes and the geomagnetic activity effect at low latitudes. J. Geophys. Res., 98, 59815991, doi: 10.1029/92JA02777. [Link]

Rajesh, P. K., C. H. Lin, C. Y. Lin, C. H. Chen, J. Y. Liu, T. Matsuo, S. P. Chen, W. H. Yeh, and C. Y. Huang, 2021: Extreme positive ionosphere storm triggered by a minor magnetic storm in deep solar minimum revealed by FORMOSAT-7/COSMIC-2 and GNSS observations. J. Geophys. Res., 126, e2020JA028261, doi: 10.1029/2020JA028261. [Link]

Rishbeth, H., 1997: The ionospheric E-layer and F-layer dynamos - A tutorial review. J. Atmos. Sol.-Terr. Phys., 59, 1873-1880, doi: 10.1016/S1364-6826(97)00005-9. [Link]

Rishbeth, H. and M. Mendillo, 2001: Patterns of F2-layer variability. J. Atmos. Sol.-Terr. Phys., 63, 1661-1680, doi: 10.1016/S1364-6826(01)00036-0. [Link]

Rishbeth, H. and I. C. F. Müller-Wodarg, 2006: Why is there more ionosphere in January than in July? The annual asymmetry in the F2-layer. Ann. Geophys., 24, 3293-3311, doi: 10.5194/angeo-24-3293-2006. [Link]

Sagawa, E., T. J. Immel, H. U. Frey, and S. B. Mende, 2005: Longitudinal structure of the equatorial anomaly in the nighttime ionosphere observed by IMAGE/FUV. J. Geophys. Res., 110, A11302, doi: 10.1029/2004JA010848. [Link]

Sassi, F., J. P. McCormack, J. L. Tate, D. D. Kuhl, and N.
L. Baker, 2021: Assessing the impact of middle atmosphere observations on day-to-day variability in lower thermospheric winds using WACCM-X. $J$. Atmos. Sol.-Terr. Phys., 212, 105486, doi: 10.1016/j. jastp.2020.105486. [Link]

Taubenheim, J., 1983: Meteorological Control of the $D$ Region. In: Roederer, J. G. (Ed.), Progress in SolarTerrestrial Physics, Springer, Dordrecht, 397-411, doi: 10.1007/978-94-009-7096-0_31. [Link]

Torr, D. G., M. R. Torr, and P. G. Richards, 1980: Causes of the F region winter anomaly. Geophys. Res. Lett., 7 , 301-304, doi: 10.1029/GL007i005p00301. [Link]

Torr, M. R. and D. G. Torr, 1973: The seasonal behaviour of the F2-layer of the ionosphere. J. Atmos. Terr. Phys., 35, 2237-2251, doi: 10.1016/0021-9169(73)90140-2. [Link]

Tsurutani, B., A. Mannucci, B. Iijima, M. A. Abdu, J. H. A. Sobral, W. Gonzalez, F. Guarnieri, T. Tsuda, A. Saito, K. Yumoto, B. Fejer, T. J. Fuller-Rowell, J. Kozyra, J. C. Foster, A. Coster, and V. M. Vasyliunas, 2004: Global dayside ionospheric uplift and enhancement associated with interplanetary electric fields. J. Geophys. Res., 109, A08302, doi: 10.1029/2003JA010342. [Link]

Walker, G. O., 1981: Longitudinal structure of the F-region equatorial anomaly-A review. J. Atmos. Terr. Phys., 43, 763-774, doi: 10.1016/0021-9169(81)90052-0. [Link]

Wang, S., S. Huang, and H. Fang, 2015: Wave-3 and wave-4 patterns in the low- and mid-latitude ionospheric TEC. J. Atmos. Sol.-Terr. Phys., 132, 82-91, doi: 10.1016/j. jastp.2015.07.002. [Link]

Zhang, X., J. M. Forbes, M. E. Hagan, J. M. Russell, S. E. Palo, C. J. Mertens, and M. G. Mlynczak, 2006: Monthly tidal temperatures $20-120 \mathrm{~km}$ from TIMED/SABER. J. Geophys. Res., 111, A10S08, doi: 10.1029/2005JA011504. [Link]

Zhang, X., J. M. Forbes, and M. E. Hagan, 2010: Longitudinal variation of tides in the MLT region: 2. Relative effects of solar radiative and latent heating. J. Geophys. Res., 115, A06317, doi: 10.1029/2009JA014898. [Link]

Zhou, Y.-L., L. Wang, C. Xiong, H. Lühr, and S.-Y. Ma, 2016: The solar activity dependence of nonmigrating tides in electron density at low and middle latitudes observed by CHAMP and GRACE. Ann. Geophys., 34, 463-472, doi: 10.5194/angeo-34-463-2016. [Link] 